\title{
Analysis of a novel mutant allele of GSL8 reveals its key roles in cytokinesis and symplastic trafficking in Arabidopsis
}

\author{
Behnaz Saatian ${ }^{1,2}$, Ryan S. Austin ${ }^{1,2}$, Gang Tian ${ }^{1}$, Chen Chen ${ }^{1,2}$, Vi Nguyen', Susanne E. Kohalmi², \\ Danny Geelen ${ }^{3}$ and Yuhai Cui ${ }^{1,2^{*}}$ (D)
}

\begin{abstract}
Background: Plant cell walls are mainly composed of polysaccharides such as cellulose and callose. Callose exists at a very low level in the cell wall; however, it plays critical roles at different stages of plant development as well as in defence against unfavorable conditions. Callose is accumulated at the cell plate, at plasmodesmata and in male and female gametophytes. Despite the important roles of callose in plants, the mechanisms of its synthesis and regulatory properties are not well understood.
\end{abstract}

Results: CALLOSE SYNTHASE (CALS) genes, also known as GLUCAN SYNTHASE-LIKE (GSL), comprise a family of 12 members in Arabidopsis thaliana. Here, we describe a new allele of GSL8 (named essp8) that exhibits pleiotropic seedling defects. Reduction of callose deposition at the cell plates and plasmodesmata in essp8 leads to ectopic endomitosis and an increase in the size exclusion limit of plasmodesmata during early seedling development. Movement of two non-cell-autonomous factors, SHORT ROOT and microRNA165/6, both required for root radial patterning during embryonic root development, are dysregulated in the primary root of essp8. This observation provides evidence for a molecular mechanism explaining the gs/8 root phenotype. We demonstrated that GSL8 interacts with PLASMODESMATALOCALIZED PROTEIN 5, a $\beta$-1,3-glucanase, and GSL10. We propose that they all might be part of a putative callose synthase complex, allowing a concerted regulation of callose deposition at plasmodesmata.

Conclusion: Analysis of a novel mutant allele of GSL8 reveals that GSL8 is a key player in early seedling development in Arabidopsis. GSL8 is required for maintaining the basic ploidy level and regulating the symplastic trafficking. Callose deposition at plasmodesmata is highly regulated and occurs through interaction of different components, likely to be incorporated into a callose biosynthesis complex. We are providing new evidence supporting an earlier hypothesis that GSL8 might have regulatory roles apart from its enzymatic function in plasmodesmata regulation.

Keywords: Arabidopsis thaliana, Callose, Cytokinesis, Callose synthase complex, GLUCAN SYNTHASE-LIKE 8, Intercellular signaling, Plasmodesmata, Symplastic trafficking

\section{Background}

Plant cell walls are rich in polysaccharides such as cellulose and callose [1]. Even though in plants callose is accumulated in the cell wall at a lower ratio compared to cellulose, it plays significant roles [2]. Callose is required for cell plate formation during cytokinesis and its

\footnotetext{
* Correspondence: yuhai.cui@canada.ca

${ }^{1}$ Agriculture and Agri-Food Canada, London Research and Development Centre, London, ON, Canada

${ }^{2}$ Department of Biology, Western University, 1391 Sandford St, London, ON N5V 4T3, Canada

Full list of author information is available at the end of the article
}

deposition and degradation at plasmodesmata (PD) are critical for regulation of symplastic trafficking [3-8].

Different from the other aspects of the cell cycle, cytokinesis is less conserved between non-plant organisms and higher plants. During cytokinesis in plants, at the end of anaphase, a tubulovesicular network is formed at the equator of dividing cells $[9,10]$. Callose deposition at the tubulovesicular network enforces widening and consolidation of tubules which will consequently lead to conversion of the network into a fenestrated sheet [11]. Ectopic endopolyploidy caused by cytokinesis defects

(c) The Author(s). 2018 Open Access This article is distributed under the terms of the Creative Commons Attribution 4.0 International License (http://creativecommons.org/licenses/by/4.0/) which permits unrestricted use, distribution, and reproduction in any medium, provided you give appropriate credit to the original author(s) and the source, provide a link to the Creative Commons license, and indicate if changes were made. The Creative Commons Public Domain Dedication waiver (http://creativecommons.org/publicdomain/zero/1.0/) applies to the data made available in this article, unless otherwise stated. 
has been observed in different organisms and cell types [12-16].

Plant cells are immobile and therefore, positional cues and information exchange between cells are critical during plant development. Intercellular signaling processes occur through either apoplastic signaling, or symplastic movement of molecules via PD [17]. It has been proposed that callose deposition/degradation at the apoplastic neck of PD regulates its size exclusion limit (SEL) and, consequently, cell to cell connectivity $[18,19]$. Although the important role of callose equilibration at PD in regulation of SEL and symplastic movement has been implicated [20], the molecular mechanism(s) linking the identified players for endogenous signaling to callose homeostasis is largely unknown.

The Arabidopsis genome has 12 genes encoding GLUCAN SYNTHASE-LIKE (GSL) [21], also called CALLOSE SYNTHASE (CALS) [22]. GSL enzymes synthesize callose in response to different developmental, physiological, and environmental signals and in various plant tissues [22-27]. Out of the 12 GSLs in Arabidopsis, GSL4, GSL6, GSL7, GSL8 and GSL12 have so far been indicated to be associated with plasmodesmata regulation [28-31].

GLUCAN SYNTHASE-LIKE 8 (GSL8) is one of the few members of the GSL family with high expression during plant development [32]. gsl8 mutants exhibit pleiotropic defects and lethality [30, 33-36], but the mechanisms underlying these phenotypes remain mostly unknown.

Here, we report a new mutant allele of GSL8 called essp8, identified in a genetic screen for mutations inducing the ectopic expression of the seed storage proteins (essp) [37-42]. We provide new experimental evidence suggesting that gsl8/essp 8 developmental defects are caused by both cytokinesis impairments and dysregulation of symplastic trafficking via PD.

\section{Results}

Developmental defects in essp8 seedlings are caused by a splice site mutation in GSL8

essp8 seedlings exhibit several developmental defects including dwarfism, formation of abnormally-developed cotyledons and true leaves, reduced growth of the root and hypocotyl, and generally delayed development compared to wild type (WT) Col-0 (Fig. 1a-c). The essp 8 mutation causes incomplete embryo lethality $(\sim 20 \%$ of the homozygous seeds failed to germinate) and thus reduced transmission in the progeny (See Additional file 1: Table S1). Examination of the siliques from a heterozygous parent show that $\sim 25 \%$ of the seeds are visually defective, being smaller, darker and shrunk compared to wild-type seeds (Fig. 1d; See Additional file 1: Table S2). The essp 8 mutation is lethal in most of the mutant seedlings, leading to their death after three weeks (Fig. 1e).
However, it can induce ectopic cell proliferation in the seedlings that survive longer (Fig. 1f). essp 8 mutants show severe defects in root tissue patterning (Fig. 1g) with bloated cells, loss of radial patterning, and develop short, swollen and often branched root hairs (Fig. 1h-i).

The essp 8 mutation was mapped on the bottom arm of chromosome 2 (See Additional file 2: Figure S1A-C) and a single non-synonymous EMS-induced point mutation (G/C to $\mathrm{A} / \mathrm{T}$ substitution) was identified in AT2G36850 (GSL8) (See Additional file 2: Figure S1D). The mutation disrupts the splice site of GSL8 at intron 22, introducing a premature STOP-codon (Fig. 1j). Disruption of GSL8 mRNA downstream of exon 22 was confirmed using RT-PCR (data not shown). GSL8 is a large integral membrane protein predicted to form sixteen transmembrane helices [43]. The transmembrane domains are clustered into an N-terminal and a C-terminal region leaving a large hydrophilic central loop within the cytoplasm (Fig. 1k). In essp8, introduction of the premature STOP-codon results in the truncation of the GSL8 protein at the fifth cytoplasmic hydrophilic loop (Fig. 1k).

To confirm that ESSP8 is indeed allelic to GSL8, four T-DNA insertion lines, SALK_11500 (gsl8-1), SALK_109342 (gsl8-2), SAIL_21_B02 (gsl8-3) and SALK_098374 (gsl8-4), were obtained (Fig. 1j). Homozygous T-DNA mutant seedlings for all four lines exhibited similar phenotypes as that of essp8 (See Additional file 2: Figure S2A-F and S3). Similar to essp8, the T-DNA alleles also showed reduced transmission in the progeny (See Additional file 1: Table S3). An allelism test was performed. F1 progeny seedlings heterozygous for two different mutant alleles of GSL8 recapitulated the morphological phenotype of homozygous gsl 8 or essp 8 mutants (See Additional file 2: Figure S2G-I). Genetic transformation of the essp8 mutant with the GSL8 coding sequence driven by its native promoter successfully rescued the mutant phenotype (See Additional file 2: Figure S4). These observations demonstrate that essp 8 is indeed a new allele of GSL8.

\section{Callose deposition at both cell plate and plasmodesmata is decreased in essp8 roots}

During plant growth and development, callose is accumulated in different tissues and cells, where it plays vital roles. Callose deposition at the cell plate and PD is required for completion of cytokinesis and physical constriction of PD, respectively [30, 35, 36]. The effect of the gsl8 mutation on callose deposition at the cell plate and PD was investigated using the callose-specific dye, aniline blue fluorochrome, in the primary root of WT Col-0, essp8, gsl8-1 and gsl8-2. In the WT root tip, bright, linear signals, representing the callose deposited at the cell plate [30] in newly divided cells, were detected (Fig. 2a). Concomitantly, the punctate fluorescent signals at the cell walls, root hairs and vascular tissues in 

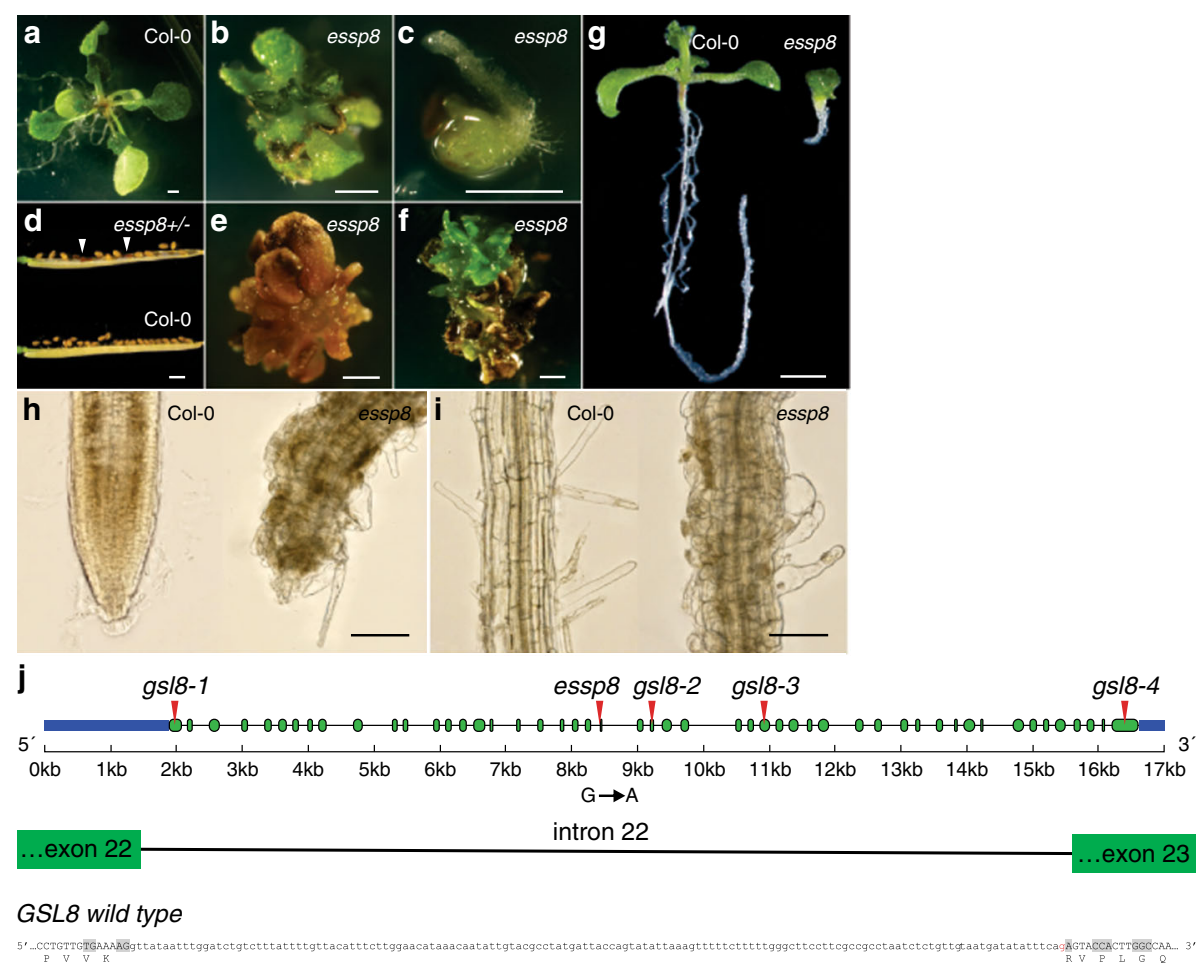

\section{GSL8 essp8 mutant}

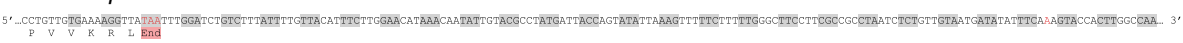

k

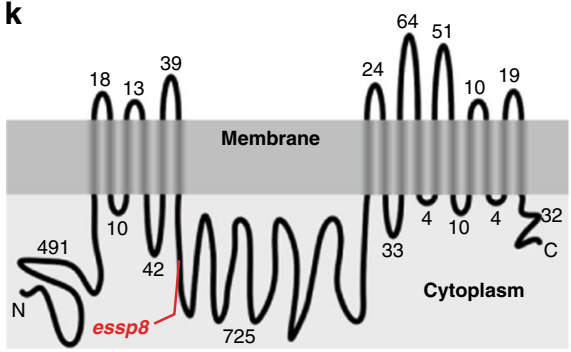

Fig. 1 Morphological phenotype of the essp8 mutant. a-c Comparison of seedling phenotypes of WT Col-0 (a) and essp8 mutants (b-c) grown on MS agar for two weeks. The essp8 roots and hypocotyls are shorter and thicker compared to the WT Col-0. $\mathbf{d}$ Siliques from a heterozygous parent showing the formation of defective seeds (white arrowheads). e Representative image showing the seedling lethal phenotype in a 3-week-old essp8 mutant. f Image showing the ectopic cell proliferation in a small percentage of mutants (10\%). $\mathbf{g}$ Ten-day-old WT and essp8 mutant seedlings showing the stunted roots in the mutant. $\mathbf{h}-\mathbf{i}$ Comparison of the root phenotype between five-day-old WT and essp 8 mutant seedlings at the root tip (h) and elongation zone (i) showing abnormally-developed root tips, having bloated cells and formation of short, swollen, and often branched root hairs in the elongation zone. $\mathbf{j}$ GSL8 gene structure showing exons (green boxes) and introns (lines). The mutation/insertion sites (red triangles) of alleles used in this work are indicated. The splice site at intron 22 is disrupted in essp 8 causing a retention of intron 22 in essp8 which establishes a premature STOP-codon downstream of exon 22. k GSL8 encodes a large transmembrane protein. GSL8 has a large cytoplasmic central loop between the transmembrane domains. The essp8 mutation results in the truncation of the GSL8 protein at the fifth cytoplasmic helix, identified by the red line. Scale bars $=1 \mathrm{~mm}(\mathbf{a}-\mathbf{f}), 200 \mu \mathrm{m}(\mathbf{g}), 50 \mu \mathrm{m}(\mathbf{h}-\mathbf{i})$

the elongation zone of the root (Fig. 2a and e) indicate callose deposition at PD [44]. In contrast to the WT, essp8, gsl8-1 and gsl8-2 roots showed weaker signal at the cell plates (Fig. 2b-d), PD (Fig. 2f-h) and in the root hairs and vasculature tissue. Quantification of callose accumulation at PD demonstrated significant reduction of callose signal in all three gsl 8 mutants compared to the WT (Fig. 2i). We thus conclude that GSL8 plays important role in callose biosynthesis and deposition at cell plates and $\mathrm{PD}$ in the primary root of Arabidopsis seedlings.

\section{GSL8 is required for the completion of cytokinesis in embryonic root}

Formation of defective cell plate during cytokinesis can cause abortion of cell division. Depending on the stage when mitosis is aborted, separation of the newly-formed nuclei or duplicated chromosomes is disrupted, leading 


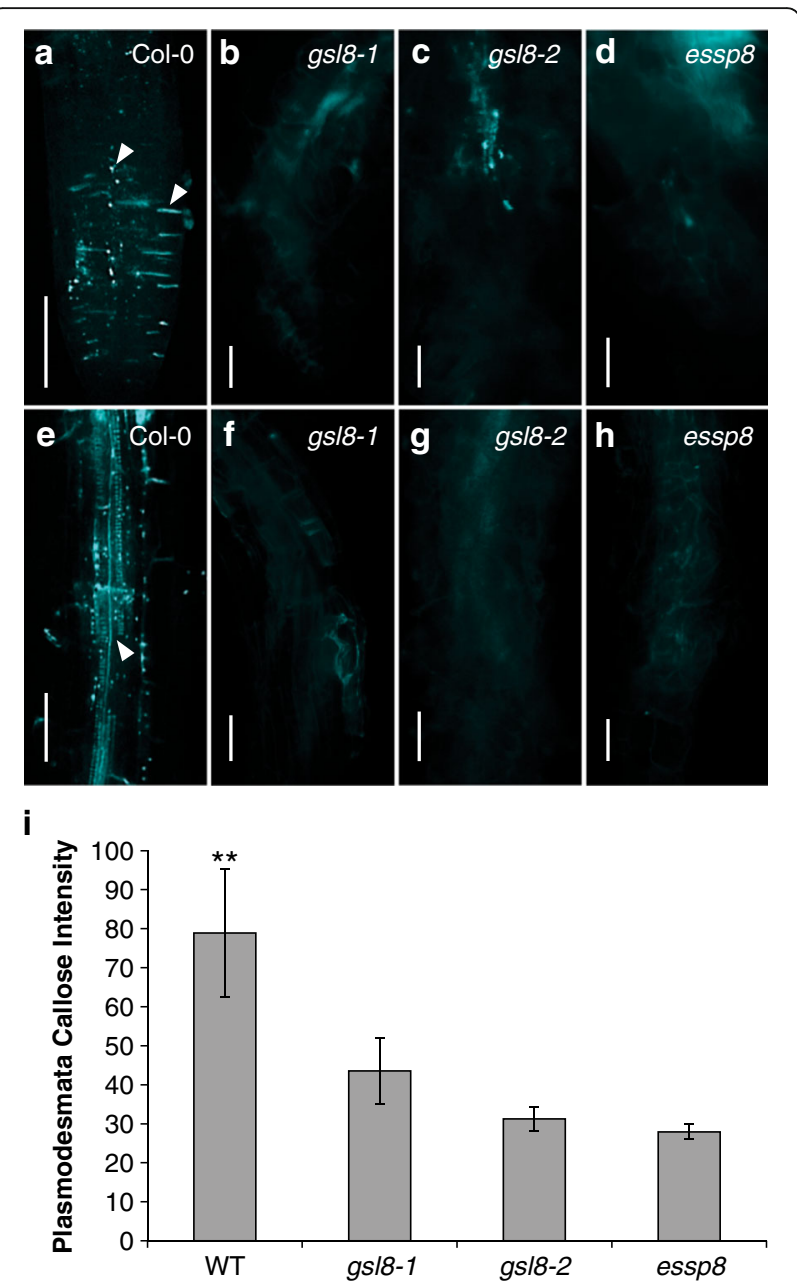

Fig. 2 Callose deposition in the primary root of gs/8 mutants. Callose accumulation was visualized using aniline blue staining in five-dayold seedlings of WT, gs/8-1, gs/8-2 and essp8. a-d Bright blue lines and dots (white arrowheads) at the root tip represent callose deposition at the cell plate and plasmodesmata, respectively, in WT (a) and gs/8 mutants (b-d). e-h In the elongation zone of the primary root, callose deposition at plasmodesmata is detected as blue dots in the root hairs, cell wall and vascular tissue (white arrowhead) in the WT (e) and gs/8 mutants (f-h). i Quantification of callose levels in gs/8 mutants compared to WT Col-0. Values represent mean \pm SEM $(n=10) .{ }^{* *} P<0.01$. Scale bars $=100 \mu \mathrm{m}$

to generation of multi-nucleated cells or cells with doubled chromosome numbers known as endomitosis [45]. To investigate whether the severe phenotypic defects in essp 8 seedlings are caused by incomplete cytokinesis, different known cytokinesis-defective mutants: hinkel [46], knolle [47], keule [48], korrigan [49] and stomatal cytokinesis-defective 1 (scd1) [50], were examined for their morphological phenotypes. All the tested cytokinesis-defective mutants are dwarf, reminiscent of essp8 seedling morphology (See Additional file 2: Figure S5A-F). knolle, keule and korrigan form fused cotyledons and fail to develop true leaves (See Additional file 2: Figure S5D-F). hinkel and scd1, similar to essp8 seedlings, form short roots and thicker leaves (See Additional file 2: Figure S5B-C).

$\mathrm{Bi}$ - or multi-nucleated cells are formed where two daughter cells fail to separate by a cross-wall. To explore if essp 8 mutant seedlings form binucleated cells, the primary root was stained with propidium iodide (PI). Binucleated cells were observed in scd1, keule, korrigan and knolle (Fig. 3a-e). Similar to the cytokinesis-defective mutants, gsl8 seedlings also have cells with more than one nucleus suggesting that gsl8 can be categorized as a cytokinesis-defective mutant (Fig. 3f-h). However, a very frequently observed defect in essp 8 root (enlarged disorganized cells with abnormal shapes) was not observed in cytokinesis-defective mutants. This result indicates that essp 8 morphological and developmental defects are only partially attributable to cytokinesis impairments.

Identification of binucleated cells in somatic tissues of essp 8 root prompted us to investigate the possibility of endomitosis. Using a centromere-labeling construct, p35S:CENH3-GFP $[35,51]$, the absolute number of chromosomes was counted in gsl8 mutant backgrounds in vivo. The diploid status of the epidermal cells in WT primary root was confirmed by detection of 5 to 10 centromeric dots (Fig. 3i). Different from WT, essp8, gsl8-2 and gsl8-4 nuclei with higher number of chromosomes (ranging from 11 to 15) were observed, indicating the presence of triploid and potentially polyploid cells in these mutants (Fig. 3j-l). Comparing the centromere numbers between WT and gsl8 mutants revealed a significant increase in all three gsl8 mutants studied (Fig. 3q). Therefore, we conclude that the essp 8 mutation can induce not only ectopic endomitosis in reproductive cells (previously shown by De Storme et al. 2013), but also in the somatic root cells at very early stages of development.

Furthermore, we examined whether polyploidization level increases with age in the essp 8 mutant. Five-day-old essp 8 roots harbored scattered single enlarged endomitotic and/or polyploid cells. Wild-type root cells were homogeneously sized containing single diploid nuclei (Fig. 3m-n and $r$ ). In contrast, a marked elevation in the number of chromosomes within the cells was observed in ten-day-old essp 8 seedlings (Fig. 3o, p and r). This result suggests that with age, seedling phenotype deterioration accompanies a significant increase in polyploidization defects which may lead to seedling lethality later on.

\section{GSL8 regulates symplastic connectivity through plasmodesmata}

Callose deposition is a highly-regulated dynamic process, which is required for adjustment of PD SEL in response to endogenous and exogenous signals [20]. Earlier, the aniline blue staining indicated the requirement of GSL8 for callose deposition at PD (Fig. 2). Thus, it was postulated that decrease in callose accumulation at PD in 

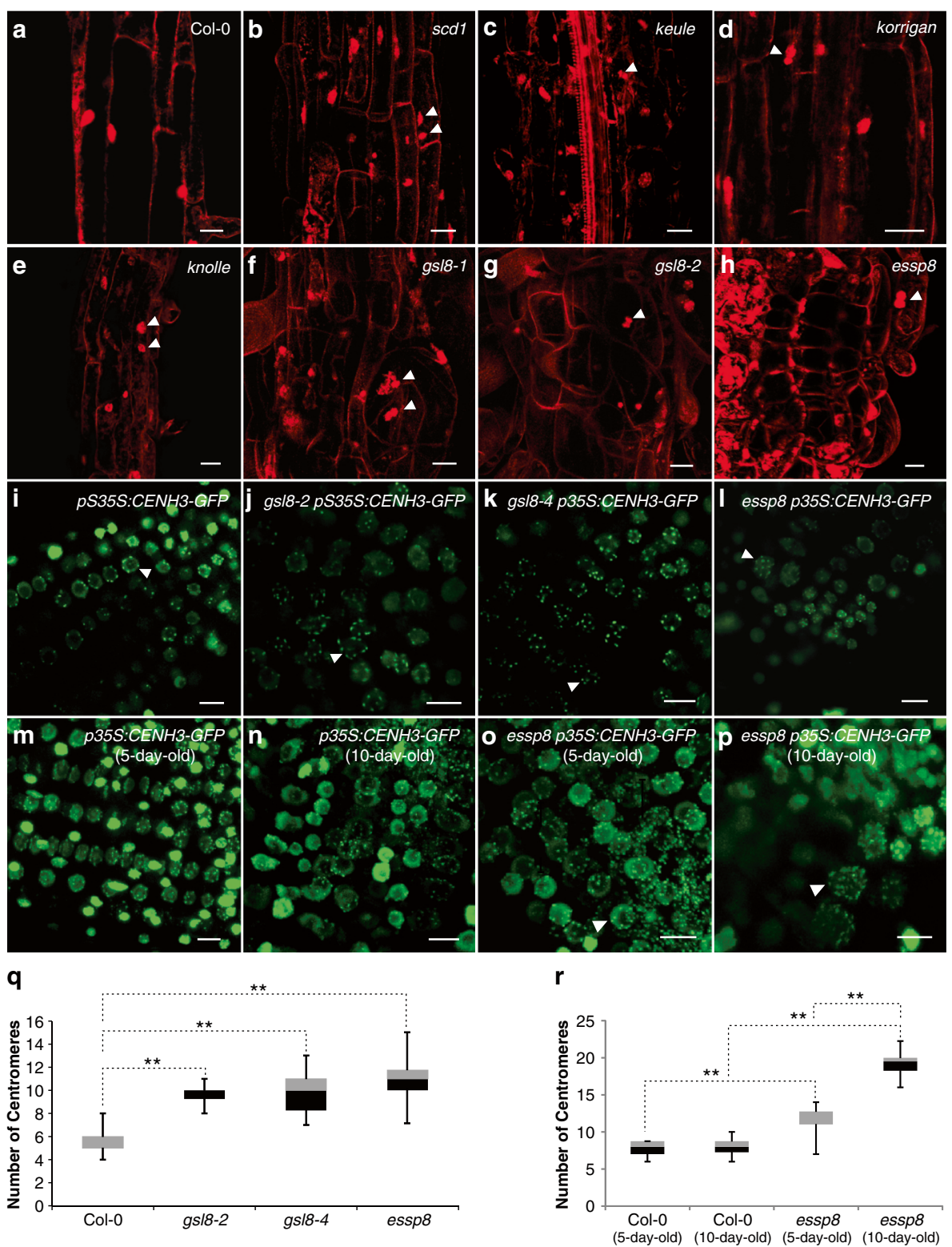

Fig. 3 Formation of binucleated and endomitotic cells in the primary root of gs/8 mutants. a-h Comparison of the number of nuclei per cell in the elongation zone of the root between WT (a), cytokinesis-defective mutants; scd1 (b), keule (c), korrigan (d) and knolle (e), and gs/8 mutants; gs/8-1 (f), gs/8-2 (g), essp8 (h). Binucleated cells are shown by white arrowheads. Propidium iodide was used to stain both nuclei and cell walls. i-I Comparison of centromere numbers (white arrowheads) in the primary roots of WT (i) and gs/8 mutants; essp8 (j), gs/8-2 (k) and gs/8-4 (I). $\mathbf{m}-\mathbf{p}$ Comparison of polyploid cells in essp8 mutant at different ages in the primary root cells of five- and ten-day-old WT (m-n), and essp8 (o-p), respectively. Polyploid cells are shown by white arrowheads. q Quantification of the centromere number per nucleus in the WT and three gs/8 mutants. $\mathbf{r}$ Quantification of centromere numbers in five- and ten-day-old primary root of WT and essp8. q-r Data were acquired from at least ten cells in an individual seedling and three biological replicates. The boxes signify the upper (grey) and lower (black) quartiles, and the median is represented by a short black line within the box for each plant line. The upper and lower "whiskers" represent the entire spread of the data. Dotted lines indicate significant differences $\left({ }^{* *} P<0.01\right.$ using Student's t-Test) between the two samples. Scale bars $=20 \mu \mathrm{m}(\mathbf{a}-\mathbf{h}), 10 \mu \mathrm{m}(\mathbf{i}-\mathbf{p})$

essp8 leads to an increase in PD SEL. To test this hypothesis, passive cell-to-cell diffusion of two fluorescent probes, Alexa flour and fluorescein $(3 \mathrm{kDa}$ and $10 \mathrm{kDa}$ in size, respectively), was investigated in essp 8 hypocotyls, as previously described [52]. The fluorescent probes were separately injected into the hypocotyls (See
Additional file 2: Figure S6A-B). Diffusion of fluorescent signal was measured as the distance between the injection site and the furthest detected signal right after injection. For the smaller probe (Alexa Fluor), fluorescent signal was detected at the site of injection and surrounding cells in both WT and essp8 (See Additional file 2: 
Figure S6C-D). However, the distance of its movement was significantly longer in essp8 (See Additional file 2: Figure S6G). In contrast, the larger probe (fluorescein) was only detected at the site of injection in nearly all cases in WT. Only a few surrounding cells showed a dim fluorescent signal, indicating its limited diffusion in WT hypocotyls (See Additional file 2: Figure S6E). The injected essp 8 hypocotyls showed strong fluorescent signal in many more of the surrounding cells (See Additional file 2: Figure S6F) and a longer traveling distance away from the injection site (See Additional file 2: Figure S6G). Diffusion pattern of Alexa Fluor in both WT and essp 8 suggests that its size $(3 \mathrm{kDa})$ is below the PD SEL in hypocotyls, whereas Lack of fluorescein diffusion in the WT proposes that $10 \mathrm{kDa}$ is possibly beyond the SEL. These results provided preliminary evidence that reduction of callose deposition at PD results in an increase in SEL in the essp 8 hypocotyl.

\section{SHORT ROOT and miR165/6 movements through plasmodesmata are dysregulated in essp 8}

During root development in Arabidopsis, the endodermis, middle cortex, and cortex are formed by timely and spatially regulated periclinal cell divisions. The formation of endodermis and cortex occurs continuously by parallel division of the cells surrounding the quiescent centre (QC) at the root tip, which is mediated by the activities of two transcription factors, SHORT ROOT (SHR) and SCARECROW (SCR) [53-55]. SHR has the ability to move from the stele cells, its domain of transcription, to a single layer of adjacent cells, and all endodermis cells $[56,57]$. SHR movement acts both as a signal from the stele and an activator of endodermal cell identity determination and cell division through the transcriptional activation of $S C R$ [56].

In essp8, embryonic root harbors disorganized cells and defective radial patterning (Fig. 1h-i). To explore whether the increased SEL of PD and root tissue patterning are related, SHR symplastic movement was investigated in $g s l 8$ mutants. A GFP-tagged version of SHR was expressed under its native promoter ( $p S H R: S H R-G F P$ ) in WT, gsl8-1, gsl8-2 and essp 8 plants. In three-day-old WT and gsl8 mutant seedlings, SHR-GFP is localized into both the nucleus and cytoplasm of stele cells, but only the nucleus of neighboring cell layers including the QC, cortex/endodermis initial (CEI), and endodermis (Fig. 4a-d). The level of SHR-GFP signal was measured in the endodermis as a percentage of the stele signal in gsl 8 mutants relative to the WT. This method has been previously implicated as a good indication of SHR movement $[58,59]$. In all gsl8 mutants, the endodermal GFP signal to stele was higher than WT with significant increase found in essp8 (Fig. 4i), indicating that SHR cell-to-cell movement is dysregulated in essp 8 root. Furthermore, the transcriptional activation of $S C R$ in the endodermis requires SHR [60]. Since symplastic movement of SHR is affected in essp8, $S C R$ expression is expected to be upregulated in essp 8 embryonic roots. Indeed, elevated level of $S C R$ transcript was detected in both five-day- and ten-day-old essp 8 roots (See Additional file 2: Figure S7). We conclude that dysregulation of PD-mediated movement of SHR leads to the ectopic activity of SHR and upregulation of SCR during early seedling development in Arabidopsis.

miR165/6 species are transcribed in the endodermis outside of the stele, and then move from the endodermis into the stele where they target the transcripts of class III homeodomain leucine zipper (HD-ZIP III) family genes $[61,62]$. To further explore whether the defective root tissue patterning in essp 8 is, at least partially, the result of dysregulated symplastic signaling, miR165/6 activity in the endodermis and stele of gsl8 mutant primary roots was investigated using a 'miRNA-sensor' system as previously described $[61,63]$. In this system, lower GFP expression is an indicative of higher miRNA activity. In WT, the GFP signal was weak in the stele and endodermis, confirming the expected miR165/6 activity in these cell layers (Fig. 4e). The GFP signal intensity was higher in the $\mathrm{QC}$, lateral and columella root cap, indicating the absence of miR165/6 activity in these tissues (Fig. 4e). In all the three gsl8 mutants, weak GFP signal was observed in the stele and endodermis (Fig. 4f-h). Notably, miR165/6 was also found to be ectopically active in the outer cell layers, as evidenced by the weak GFP signals in the epidermis, QC, and lateral and columella root cap (Fig. 4f-h). Measuring the GFP intensity in $g s l 8$ mutants' roots relative to the WT indicates significant decreases in all the three mutants (Fig. 4j).

To determine that defective cell plate formation in essp 8 seedlings is not causing the impairment of PD biogenesis, we used a PD marker, PLASMODSMATA-LOCALIZED PROTEIN 5 (PDLP5), to test its localization in the WT and essp8. The p35S:PDLP5-GFP construct was introduced into WT Col-0, and heterozygous GSL8/gsl8-1 and GSL8/essp8 plants. PDLP5-GFP signals were detected at punctate particles at the cell membrane in the elongation zone of their roots, suggesting that it is associated with the PD apertures [64] and PD biogenesis is not affected by defective cell plate formation in gsl8 mutants [65] (Fig. 5a-c). Taken together, these results reveal that loss of callose deposition at PD in essp8 seedlings causes relaxation of PD-mediated intercellular signaling.

\section{GSL8 interacts with plasmodesmata localized proteins}

It has been predicted that GSL might be part of a hypothetical complex called callose synthase complex (CalS) [34]. To investigated the composition of this complex, we selected a few candidates to test their possible interaction with GSL8 as follows: 1) previously suggested 

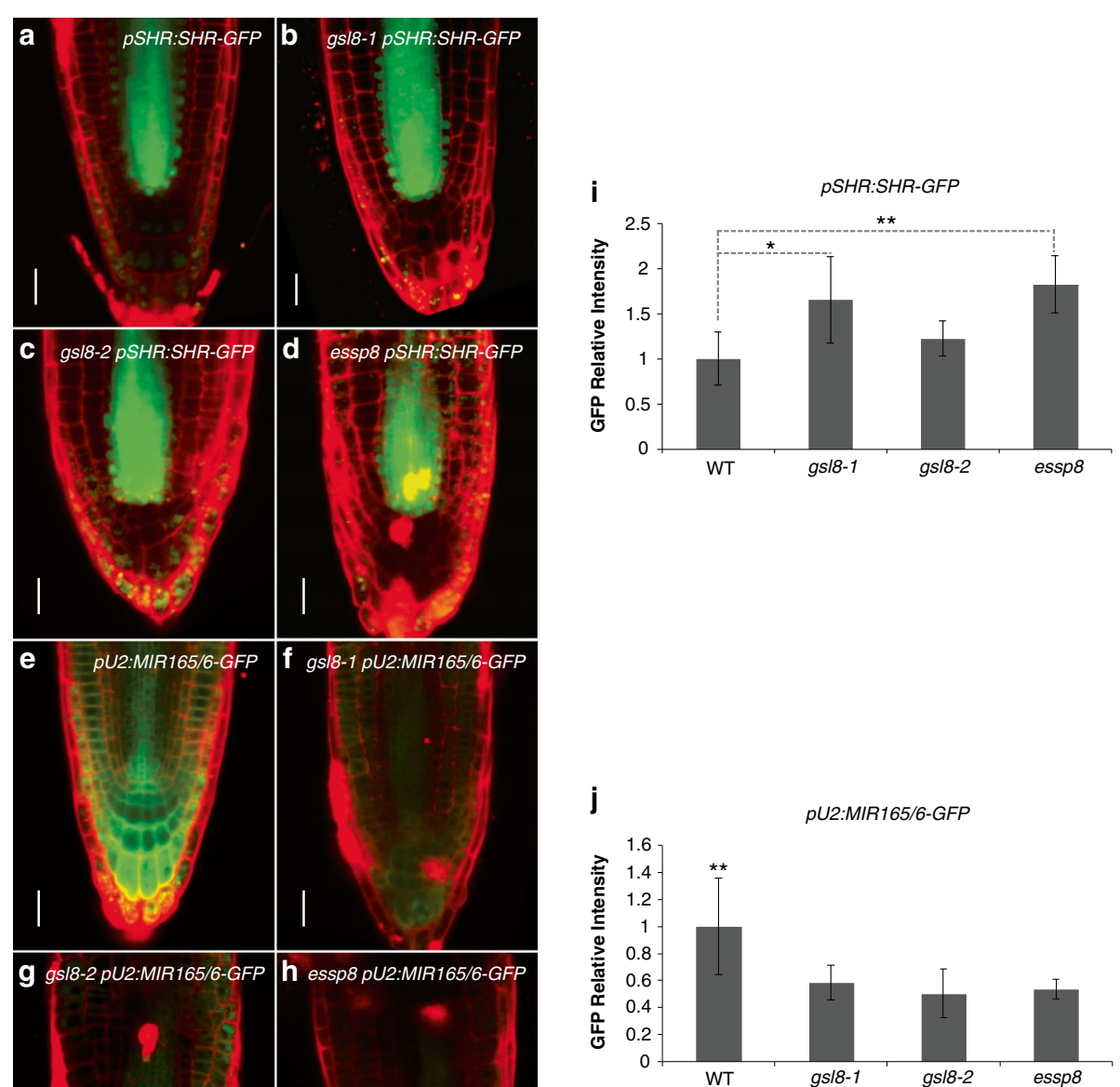

Fig. 4 Symplastic movement of SHR and miR165/6 is altered in essp8. a-d Localization of SHR-GFP fusion proteins in the primary root of three-day-old WT (a), gs/8-1 (b), gs/8-2 (c) and essp8 (d). e-h miR165/6 activity in transgenic lines with pU2:MIR165/6-GFP in primary root of three-day-old WT (e), gs/8-1 (f), gs/8-2 (g) and essp8 (h). Roots were stained with PI to visualize the cell wall. Scale bars $=20 \mu \mathrm{m}$. i-j Measurement of GFP ratio in endodermal cells to stele relative to the WT (i) and quantification of GFP intensity in gs/8 mutants' primary root in gs/8 mutants (j) relative to WT. Values represent mean \pm SEM $(n=10),{ }^{*} P<0.05,{ }^{* *} P<0.01$
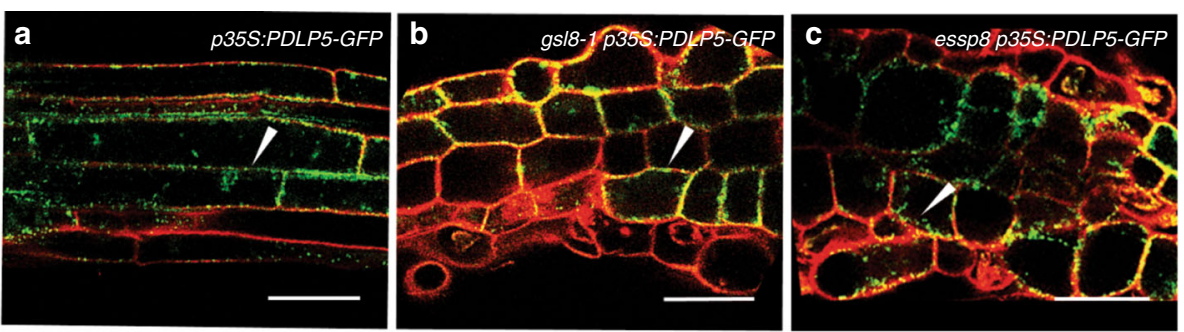

Fig. 5 Subcellular localization of PDLP5-GFP in WT and gs/8 primary root. a-c In the WT background, PDLP5-GFP is localized at the cell membranes in a dotted pattern in the primary root (a). Similarly, in the gs/8-1 (b) and essp8 (c) backgrounds, the PDLP5-GFP signal can be detected at the cell periphery (white arrowheads). Scale bars $=50 \mu \mathrm{m}$ 
components of CalS, including at least one of the GSLs, UDP-glucose transferase 1 (UGT1) and sucrose synthase (SuSy) [24, 66-68]; 2) proteins proposed to be involved in PD SEL regulation, including callose degrading enzymes called glucanases [19] and PD-localized proteins (PDLPs) [65]; 3) SCD1, as it plays a role in cytokinesis [69], and $s c d 1$ seedling showed phenotype similar to essp8 (See Additional file 2: Figure S5); and 4) GSL10, since GSL8 and GSL10 are the most closely-related members of the GSL family (clustered into the same subfamily) according to the phylogenetic tree for the Arabidopsis GSL family (See Additional file 2: Figure S8), and gsl8 and gsl10 loss-of-function mutants show similar phenotypes during microspore mitosis and sporophyte development [34]. We thus speculated that GSL8 and GSL10 might form a heterodimeric complex, in which the absence of one member would disrupt the function of the complex. Altogether, six candidates including SUCROSE SYNTHASE 1 (SUS1), UDP-GLYCOSYLTRANSFERASE (UDPG), PDLP5, a $\beta$-1,3-glucanase called AtBG_PPAP, SCD1 and GSL10 were selected to investigate their interaction with GSL8 in vivo. First, we performed bimolecular fluorescence complementation (BiFC) assays to test the interaction of AtBG_PPAP, PDLP5, UDPG, SCD1 and SUS1 with GSL8. All the five tested proteins showed an interaction with GSL8 in planta (Fig. 6a-e). Subcellular localization of GSL8-YFP fusion shows its localization at the cell membrane (Fig. 6f). No interaction was detected between GSL8-YC and GmIFS2-YN, an ER membrane-localized protein from soybean [70], and pEG100-YN which were used as negative control (Fig. $6 \mathrm{~g}-\mathrm{h})$. The localization of the interacting proteins was also visualized by their YFP signals (See Additional file 2: Figure S9). Next, we used Förster resonance energy transfer (FRET) to further validate these interactions.

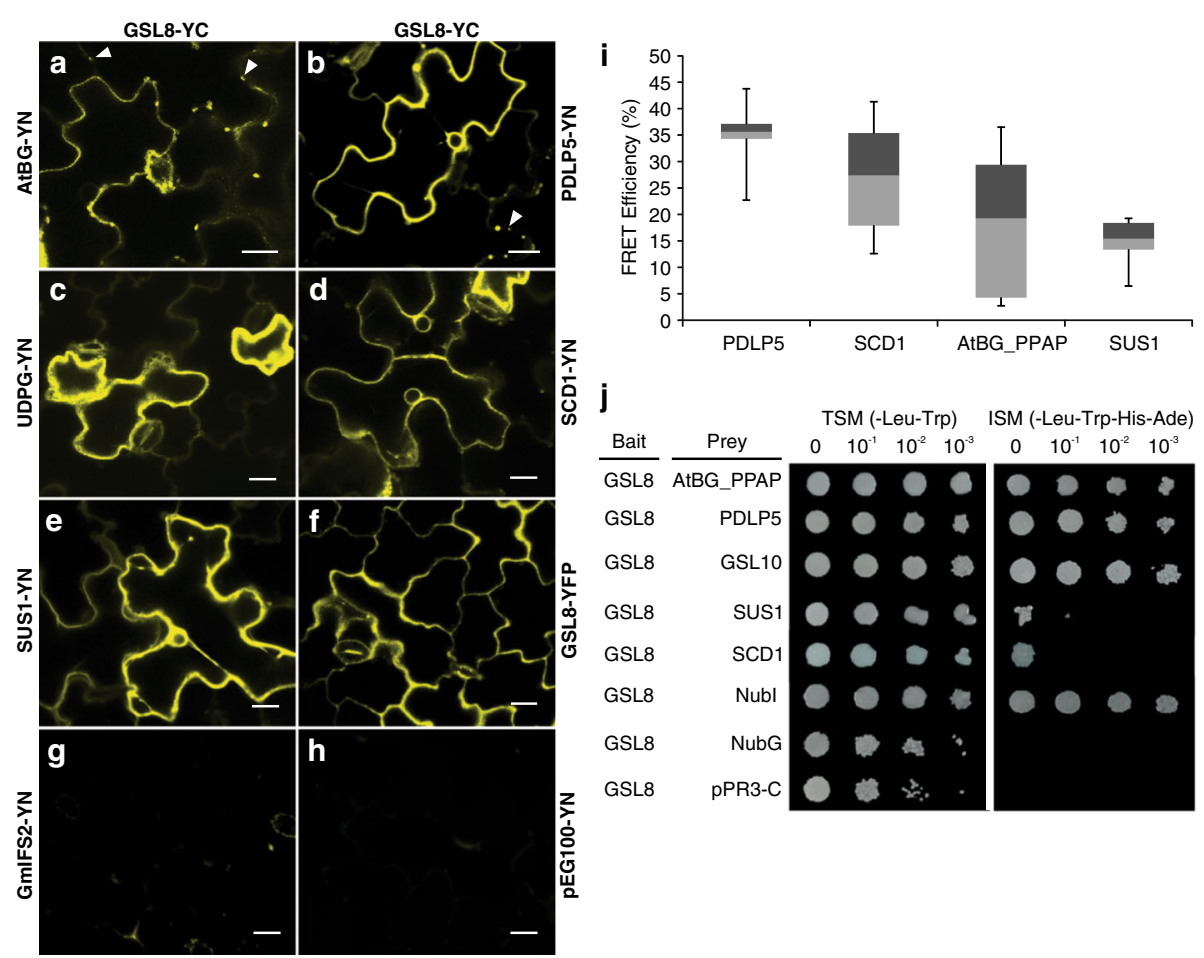

Fig. 6 Analysis of GSL8 physical association with proteins involved in callose synthesis. a-f BiFC assay showing the interaction between YC fusion of GSL8 and YN fusions of AtBG_PPAP (a), PDLP5 (b), UDPG (c), SCD1 (d) and SUS1 (e). Interactions between GSL8 and AtBG_PPAP/ PDLP5 appear to be localized at the cell membrane and plasmodesmata (white arrowheads) (a-b). GSL8 interacts with UDPG and SUS1 in the cytoplasm and on the ER (c and $\mathbf{e}$ ). Interaction of GSL8 with SCD1 occurs at the cell membrane and the cell plate (d). Subcellular localization of GSL8-YFP fusion shows its localization at the cell membrane ( $\mathbf{f}$ ). There was no interaction between GSL8-YC and GmIFS2-YN, an ER membrane-localized protein from soybean [70], and pEG100-YN which were used as negative control (g-h). Scale bars $=20 \mu \mathrm{m}$. i FRET confirms GSL8 interaction with PDLP5, SCD1, AtBG_PPAP and SUS1. No interaction was found with UDPG and free CFP (data not shown). The boxes signify the upper (dark grey) and lower (light grey) quartiles, and the median is represented by a short black line within the box for each. The upper and lower "whiskers" represent the entire spread of the data. The data used for FRET efficiency calculation and statistical analysis were obtained from three independent experiments and three biological replicates for each experiment. In all cases, values reported are the mean \pm SEM. $\mathbf{j}$ MYTH assay. Colonies of transformed yeast cells growing on transformation selection media (TSM) and interaction selection media (ISM) indicate successful interaction of bait (GSL8) and prey (AtBG_PPAP, PDLP5, GSL10, SUS1 and SCD1). Nubl was used as a positive control. NubG and empty vector were used as negative controls 
FRET analysis showed the potential interaction between GSL8 and SUS1, AtBG_PPAP, PDLP5 and SCD1. No interaction could be detected between GSL8 and UDPG (Fig. 6i, See Additional file 2: Figure S10). Considering the higher sensitivity of FRET compared to BiFC, we suggest that GSL8 interaction with UDPG might occur indirectly through another protein. It needs to be noted that, regardless of our exhaustive attempts, propagation of the GSL10 cDNA in bacteria was not successful and thus its interaction with GSL8 could not be tested by BiFC and FRET. Lastly, to confirm the interactions identified by both BiFC and FRET, a membrane yeast two hybrid system (MYTH) [71] was employed. The MYTH results confirm the interaction of GSL8 with AtBG_PPAP, PDLP5, GSL10, SCD1 and SUS1 in yeast, albeit the interactions with SCD1 and SUS1 are rather weak (Fig. 6j).

The possibility that GSL8 and GSL10 interact to form a complex was further tested using a genetic approach. It was hypothesized that gsl8 gsl10 double mutant shows a similar phenotype to that of gsl8 or gsl10 single mutants if GSL8 and GSL10 form a heterodimeric complex. Due to the essential role of GSL10 in gametophytic development, no homozygous gsl10 mutants could be recovered after screening several T-DNA insertion lines. Hence, a conditional gslo gsl10 double mutant was generated using an artificial miRNA under the control of an estradiol-inducible promoter [72]. The mock treated fourteen-day-old XVE:aMIRGSL8/GSL10 transgenic seedlings did not show any obvious defects compared to the WT, whereas the transgenic seedlings treated with $\beta$-esteradiol phenocopied the $g s l 8-1$ phenotype and did not exhibit more severe defects compared to gsl8 single mutant (See Additional file 2: Figure S11A-D). Analysis of the GSL8 and GSL10 transcript levels in XVE: $a$ MIRGSL8/GSL10 treated seedlings confirmed their downregulation compared to WT and mock-treated seedlings (See Additional file 2: Figure S11E). This result is consistent with a scenario that GSL8 and GSL10 are not functionally-redundant, rather, they become functional by forming a dimer which might be part of the callose synthase complex.

\section{Discussion}

\section{Polyploidization as a cause of $g s / 8$ lethality}

Callose is required for completing plant cytokinesis and proper cell wall formation $[2,8,29,73]$. Previous reports have shown that loss-of-function mutations in GSL8 cause defects in cell plate and cell wall formation in reproductive tissues [30, 33-36]. Our findings are in agreement with the previous studies and reconfirm the cytokinesis defects in the newly identified allele of GSL8, essp8. Furthermore, we showed that gsl8 mutation induces ectopic polyploidization and endomitosis, both in the meristematic tissue and elongating cells in the primary root of the seedling. Our results provide evidence that cytokinesis defects in gsl8 mutants are beyond the reproductive tissues and affect both somatic and reproductive cells.

The cause(s) of gsl8 knockout mutants' lethality is still unclear. Loss of proper chromosome condensation and segregation during successive cell divisions has been suggested as one of the potential reasons leading to growth arrest [35]. Segregation of the replicated chromosomes can become too complicated in polyploid or endomitotic nuclei as they go through consecutive cell divisions [74]. The significant increase in the number of polyploid and/or endomitotic cells in older essp 8 seedlings suggest that accumulative polyploidization caused by defects in cell plate formation might induce a premature arrest of cell division in proliferating tissues and, consequently, cause cell death. Death through mitotic catastrophe and polyploidization has been reported in a number of species [75-80].

\section{Controlled symplastic movement of SHR and miR165/6 requires GSL8}

Symplastic signaling through PD is a dynamic process [81]. However, it is still not clear how callose synthases regulate PD and what other molecular components are required for this regulation. GSL8 was previously shown to be associated with PD regulation in leaf epidermal cells [30]. Expression analysis of GSL8 indicated its high expression in the vasculature and actively dividing cells $[32,33]$. In the vasculature, callose is mostly deposited at PD. A recent study suggested that an effective auxin gradient is established through GSL8-mediated callose deposition at PD, leading to downregulation of symplastic permeability [52]. Our results showed a significant decrease of callose accumulation in the primary root of all studied gsl8 mutants. Correlating with a reduction of callose accumulation at PD, the cell-to-cell diffusion assay demonstrated that the essp 8 mutation results in an increase in symplastic movement in hypocotyls, which consequently permits passive diffusion. Our finding also indicates that PD defects in gsl8 mutants are not restricted to epidermal cells, as was previously documented in chorus [30].

Our work reveals that SHR and miR165/6 distribution patterns are altered in $g s l 8$ mutants and provides a molecular explanation for their root phenotype. SHR is required for cell division and endodermis differentiation [53, 56, 82, 83]. Ectopic movement of SHR induces an increase in the number of cell layers, where the cells exhibit endodermal characteristics [83-85]. SHR abundance changes dynamically during root development, and its dose regulates middle cortex formation and periclinal cell division. High levels of SHR in the endodermal cells inhibit periclinal cell division [86]. Here, we provide 
new evidence that SHR cell-to-cell movement is dysregulated in essp 8 mutants as shown by an increase in endodermal SHR-GFP relative to the WT (Fig. 4I). Consistent with a previous finding [86], we observed loss of periclinal cell division and middle cortex formation in ten-day-old seedlings (See Additional file 2: Figure S3). As essp 8 seedling ages, root tissue layers become more disorganized. Therefore, we conclude that the essp 8 root phenotype is likely to be caused, at least in part, by dysregulation of SHR symplastic movement.

SHR directly binds to the $5^{\prime}$ upstream regions of MIR165A and MIR166B to activate their transcription [61]. Mature miR165/6 will move from endodermis to stele where they suppress the expression of HD-ZIP III family genes $[87,88]$. Our analysis revealed that the movement of mature miR165/6 is dysregulated in primary root of gsl8 mutants, suggesting that GSL8-mediated callose deposition at PD is required for regulation of miR165/6 trafficking. Importantly, the defects in vasculature tissue patterning in gsl8 mutants are reminiscent of the phenotype of MIR165/6 overexpression lines and HD-ZIPIII quadruple mutants [61]. Hence, we suggest that ectopic activity of miR165/6 in the primary root of essp 8 could be, at least partially, responsible for the essp 8 root phenotype. However, as the SHR/SCR complex regulates MIR165/6 expression [61, 62], it still needs to be further investigated whether the elevated miR165/6 activity in $g s l 8$ is a direct effect of an increase in its bidirectional PD-mediated movement, or is due to the elevated level of SHR in the endodermal cells, or is caused by both. It is worth noting that our observation with gsl8 loss-of-function mutants is complementary to a previous study showing restriction of SHR and miR165/6 PD-mediated movement in a gsl12 gain-of-function mutant [29]. Our data support the notion that GSL8-mediated callose deposition at PD is required for regulation of cell-to-cell communication during early seedling development. Although it is challenging to discriminate the defects caused by cytokinesis impairment and loss of callose deposition at the PD, we showed that PD biogenesis is unlikely to be affected in essp 8 mutants. We conclude that dysregulation of symplastic trafficking is due to the reduced amount of callose deposited at the PD and, consequently, PD relaxation.

Two other members of the Arabidopsis GSL family, GSL7 and GSL12, were shown to be involved in callose biosynthesis at the PD [29, 89, 90]. GSL7 is expressed in the vasculature system and is required only for callose deposition at the phloem PD and sieve plates [31, 91]. gsl7 mutants do not display any obvious macroscopic phenotypic defects, suggesting that GSL7 has no biological function other than phloem-specific PD callose synthesis. Vaten et al. (2011) suggested a role for GSL12 in PD regulation using an inducible expression system for GSL12 gain-of-function mutants [19, 29]. They showed that gain of function mutations or ectopic expression of GSL12 leads to callose accumulation and plasmodesmatal connectivity decrease in the root [29]. The lethality of essp 8 single mutant rules out the possibility of GSL8 and GSL12 being functionally redundant; however, it suggests that the GSL enzymes have similar functions. Taken together, previous studies and our current data indicate that the spatial regulation of GSLs and their function play critical role in regulating plasmodesmal function during early seedling development in Arabidopsis.

\section{A multi-subunit CalS complex in plasmodesmata aperture regulation}

Callose biosynthesis and its deposition need to be highlyregulated. It has been proposed that GSLs, e.g. GSL8, are integrated into an extremely specialized protein complex to carry out callose synthesis. The mechanisms employed by $\beta$-1,3-glucanases, for degrading callose, and by PDLPs, for inducing callose deposition at PD, have remained unclear. Based on our observations, here we propose that regulation of the callose level at PD and the balance between the activities of enzymes synthesizing and degrading callose occurs through the direct interaction of GSL8 and AtBG_PPAP. Furthermore, as was previously proposed [20], PDLP5 is likely to induce and modulate callose deposition at PD through its direct interaction with a callose synthesis enzyme. A recent study suggested that callose deposition at PD by GSL8 occurs through an independent pathway from PDLP5 [28]. Here, we propose that callose induction at PD by PDLP5 is (likely) to be GSL8mediated.

It was previously suggested that UGT1 transfers UDP-glucose (UDP-Glc) from SuSy to CalS, and therefore, channels callose deposition to the targeted subcellular location $[67,68]$. GSL8 interaction with SUS1 and UDPG was shown to occur in the cytoplasm and on the endoplasmic reticulum (ER) in BiFC assay; however, GSL8 interaction with UDPG was not confirmed by FRET. Considering the subcellular localization of these proteins (See Additional file 2: Figure S9), our data lead us to speculate that UDPG interaction with GSL8 might be indirect. Thus, similar to the case of the cellulose synthase (CESA) complex [92, 93], sucrose synthase is likely to be incorporated into the callose synthase complex to channel UDP-Glc into glucan synthesis. Obviously, other components of sucrose degradation and biosynthesis pathway should be tested to identify other related players that directly interact with GSL8.

A recent study has shown that SCD proteins, including SCD1, are involved in different membrane trafficking events required not only for cytokinesis, but also for cell expansion [69]. During cell plate formation, SCD1 is 
involved in vesicular trafficking to the equator of the dividing cell [50]. Callose deposition converts the fused vesicles into the plate [73]. The GSL8-SCD1 interaction was detected at the cell membrane in BiFC and FRET, and showed weak interaction in MYTH. This finding indicates that there is a GSL8-SCD1 interplay. It is already known that secondary PD are formed post-cytokinesis, possibly during cell expansion; however, how this happens remains unclear [94]. Future investigations are needed to elucidate whether the GSL8-SCD1 interplay is restricted to cell plate formation and/or is somehow linked to secondary PD formation.

GSL10 has remained as one of the least studied members of the GSL family due to severe gametophyte defects in the mutant lines. A previous study speculated the existence of a GSL8-GSL10 heterodimeric callose synthase-like complex [34]. Our observations support this hypothesis based on our MYTH result (Fig. 6j) and the observation with the gsl8 gsl10 conditional double mutant (See Additional file 2: Figure S11). Future study on co-localization of GSL8 and GSL10 will provide further evidence on existence of such a complex. Similar heteromeric complex have been shown for CESA complexes formed by three different CESA proteins $[95,96]$.

\section{Conclusion}

Our current study reports the critical role of GSL8 during early seedling development in Arabidopsis. We show how callose biosynthesis by GSL8 is required to complete cytokinesis during cell division, and to regulate cell-to-cell communication. Callose accumulation occurs through interaction of different components, likely to be incorporated into a callose biosynthesis complex to highly regulate callose deposition at the PD. Our observations, for the first time, provide new evidence supporting an earlier hypothesis that GSL8 might have regulatory roles apart from its enzymatic function in PD regulation (see model in Fig. 7). Further studies along these lines will probably result in dissection of the other components that mediate callose biosynthesis at the PD and control PD SEL.

\section{Methods}

\section{Plant material}

Due to the lethality of gsl8 mutants, all lines were propagated as heterozygotes. essp 8 was identified in a screen of EMS-mutagenized population [37]. Seeds for WT Col-0, Ler, and different T-DNA lines used in this study (See Additional file 1: Table S4) were ordered from Arabidopsis Biological Resource Center (ABRC).

\section{Next-generation mapping of essp8}

For genetic mapping of the essp 8 mutation, M2 plants from a Col-0 background were crossed with WT plants of the Ler accession. A total of 100 two-week-old seedlings with essp $8 \mathrm{dwarf}$ phenotype were selected from the F2 segregating population and used for bulked-segregant analysis (BSA) and rough-mapping. Pooled genomic DNA (gDNA) was used for BSA with 22 pairs of simple sequence length polymorphism (SSLP) markers [97]. The genomic interval harbouring the essp 8 mutation was narrowed down using PCR-based rough-mapping (See Additional file 1: Table S5). Pooled gDNA extracted from 64 seedlings were used as template for next-generation sequencing (NGS) [98]. The NGS library was generated using NGS library preparation kit (Zymo Research). Sequencing was performed on the Illumina MiSeq (Illumina, USA).

\section{Histochemical assays}

For callose staining, a stock solution of $0.1 \mathrm{mg} / \mathrm{ml}$ aniline blue fluorochrome (Biosupplies Australia PTY Ltd.) was prepared in distilled water. Prior to use, the stock solution was diluted 1:3 with $0.1 \mathrm{M} \mathrm{K}_{3} \mathrm{PO}_{4}, \mathrm{pH} 12.0$. Roots of seven-day-old Arabidopsis seedlings were incubated with fluorochrome staining solution for $30 \mathrm{~min}$ then washed with $0.1 \mathrm{M} \mathrm{K}_{3} \mathrm{PO}_{4}, \mathrm{pH} 12.0$ buffer and imaged on a Zeiss Axioscope 2 (Zeiss, Germany) compound fluorescence microscope using a UV laser. The microscope was integrated with a Nikon DS-Ri2 digital camera using the ACT-1 software (Nikon, Japan).

To stain the cell walls with PI [99], Arabidopsis roots were immersed in $1 \mu \mathrm{g} / \mathrm{ml}$ solution for $3 \mathrm{~min}$. To visualize both cell walls and nuclei, $100 \mu \mathrm{g} / \mathrm{ml}$ PI solution was used. Roots were stained for at least $5 \mathrm{~min}$ and rinsed twice with distilled water. PI-stained roots were imaged on a Leica TCS SP2 Laser Scanning confocal microscope (Leica, Germany) using $543 \mathrm{~nm}$ excitation and $610-630 \mathrm{~nm}$ emission.

For PD SEL assay, seeds were allowed to germinate in the dark for seven days. Dextran, Alexa Fluor ${ }^{\circ}$ 488; 3,000 MW, Anionic (ThermoFisher Scientific) and Dextran, fluorescein, 10,000 MW, Anionic (ThermoFisher Scientific) were dissolved in Tris-EDTA buffer, $\mathrm{pH} 8.0$ at concentrations of $100 \mathrm{mg} / \mathrm{ml}$ and $50 \mathrm{mg} / \mathrm{ml}$, respectively. Prior to use, the stocks were diluted in Tris-EDTA buffer at a ratio of 1:10. The hypocotyls were obtained by cutting the seedlings at the hook. For each sample, $1 \mu \mathrm{l}$ of the diluted probe was injected into the hypocotyl at the cut site using a Hamilton Gastight syringe (Hamilton). Movement of the probe was analyzed immediately by imaging on a Leica TCS SP2 Laser Scanning confocal microscope (Leica) using $488 \mathrm{~nm}$ excitation and 515 to $530 \mathrm{~nm}$ emissions.

\section{Generation of transgenic plants}

Except from the complementation, the rest of the transgene constructs were generated using the Gateway ${ }^{\text {rm }}$ system 


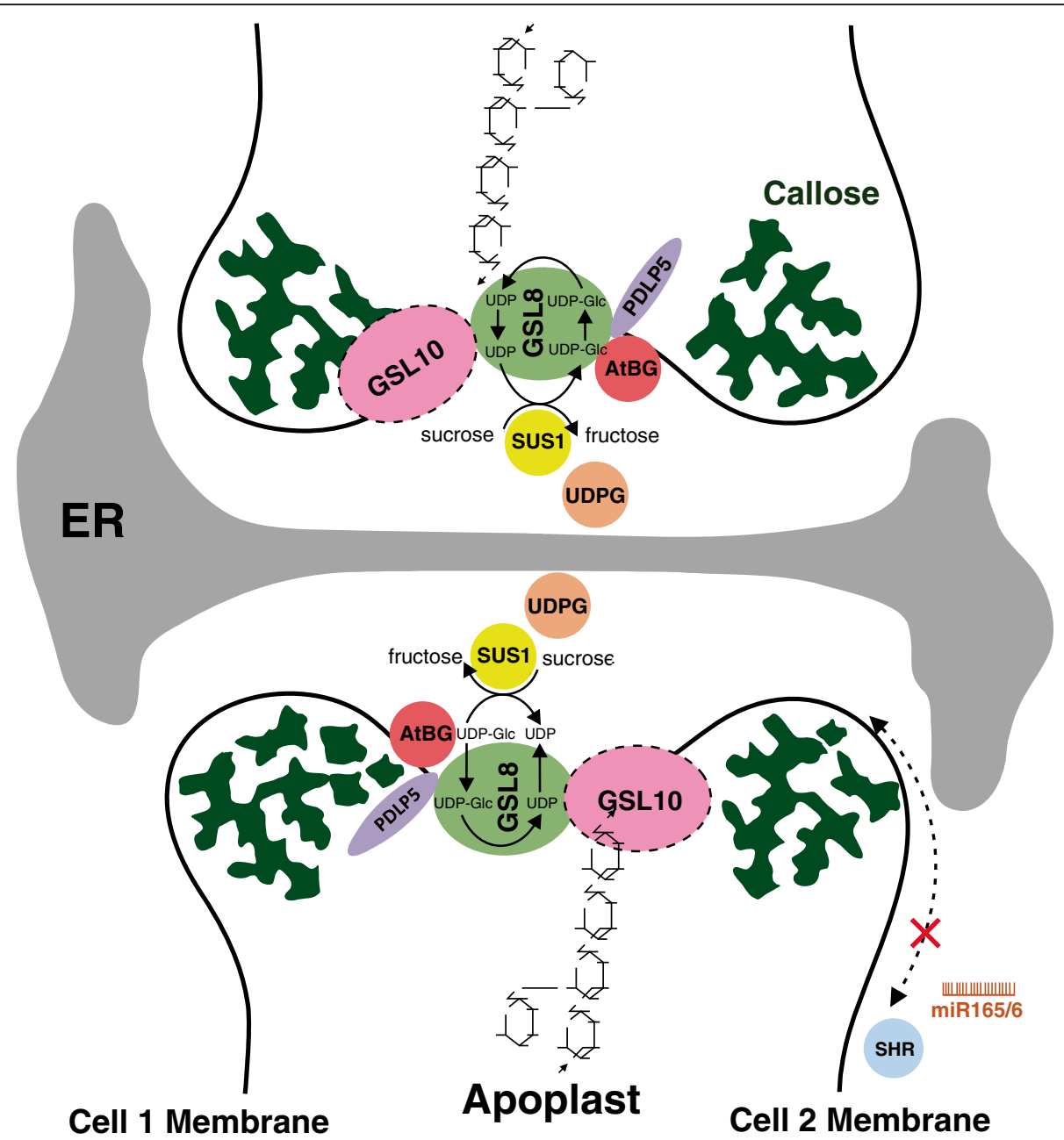

Fig. 7 Proposed model of callose deposition regulation at plasmodesmata. GSL8 (possibly GSL10 as well) catalyzes the synthesis of callose that is deposited at the neck of plasmodesmata. UDP-Glc is the callose precursor that is released from sucrose hydrolysis by SUS1 with the help of UDPG, and then channeled to GSL8 through the GSL8-SUS1 physical interaction. Conversely, there is another family of proteins including AtBG_PPAP that degrade callose. The GSL8-AtBG interaction observed in this work suggests a direct synthesizer-degrader interaction to control the deposition level of callose at plasmodesmata through an as yet unknown mechanism, which might involve PDLP5. This highly regulated callose deposition at plasmodesmata allows the proper symplastic movement of SHR and miR165/6 during development

(Invitrogen) [100]. Floral dipping of plants were carried out as described previously [101].

To complement essp8, the translational cassette for GSL 8 was generated by first, synthesizing the $2.7 \mathrm{~kb}$ sequence upstream of the Start codon harboring the native promoter, the $5^{\prime}$ untranslated region (UTR), followed by GSL8 coding sequence (BIO BASIC Int.). The synthesized cassette was subcloned into the modified yeast-compatible pGREEN vector using TAR-cloning [102] through homologous recombination in yeast [103].

To create the SHR-GFP translational fusion construct, a $3 \mathrm{~kb}$ genomic fragment harbouring the promoter, the 5 ' UTR, and the genomic sequence (not including the STOP codon) was amplified from Arabidopsis gDNA (See Additional file 1: Table S6), and cloned into the pMDC107 vector [72]. The construct was transformed into plants by floral dipping [101]. Transgenic pSHR:SHR-GFP plants were selected on MS agar media containing $50 \mu \mathrm{g} / \mathrm{ml}$ hygromycin B. The PDLP5-GFP expression construct ( $p 35$ S:PDLP5-GFP) was generated by amplifying the cDNA and cloning it into the pEarleyGate103 [104] using the Gateway ${ }^{\text {ran }}$ system (Invitrogen) [100].

Transgenic seeds expressing the centromere labeling construct ( $p 35 S: C E N H 3-G F P$ ) were described previously [35]. To visualize the centromeres in gsl8 mutants, plants homozygous for $p 35 S: C E N H 3-G F P$ were crossed with GSL8/essp8, GSL8/gsl8-2 and GSL8/gsl8-4 plants. The F2 plants were used for imaging and quantifying the number of centromeres.

To test the miR165/6 activity in gsl8 mutants, previously described miR156/6 sensor line [61] was crossed 
with heterozygous GSL8/gsl8 plants and F2 seedlings were used for analysis and imaging.

The Web Micro Designer (WMD, http://wmd3.weigelworld.org/cgi-bin/webapp.cgi) was used for designing artificial miRNAs (amiRNAs) against both GSL8 and GSL10 genes. To generate the XVE:aMIRGSL8/GSL10 construct, first the amiRNA sequence was introduced into the pRS300 vector [105] as the backbone to create aMIRGSL8/GSL10 which was then subcloned into the donor vector pDONR221 (Invitrogen). The donor construct was then recombined into the pMDC7 Gateway-compatible destination vector [72]. In pMDC7, the aMIRGSL8/GSL10 transgene is controlled by an estradiol-inducible promoter. WT Col-0 plants were transformed with the construct by floral dipping [101]. Transgenic plants were selected on MS agar media containing hygromycin B. T2 transgenic seeds were sown on MS agar media containing $100 \mu \mathrm{M} \beta$-estradiol or dimethyl sulfoxide (DMSO) as a mock control.

\section{Gene expression analysis}

For quantitative reverse transcription-PCR (qRT-PCR), total RNA was isolated from $\sim 100 \mathrm{mg}$ of plant tissue using the RNeasy Mini Kit (Qiagen). The High Capacity cDNA Reverse Transcription kit (ABI) was used to reverse transcribe total RNA into cDNA with random primers from the kit. qRT-PCR was performed using the SsoFast EvaGreen Supermix kit (Bio-Rad Laboratories, Inc.) with the Bio-Rad CFX96 real-time PCR detection system (Bio-Rad Laboratories, Inc. USA). The data shown are the average of three technical and three biological replicates. GLYCERALDEHYDE-3-PHOSPHATE DEHYDROGENASE (GAPDH) was used as the internal reference [106]. PCR primers used in qRT-PCR are listed in Additional file 1: Table S6.

\section{Bimolecular fluorescent complementation}

Full-length cDNA was used for the BiFC experiment. Amplified cDNA was cloned into pEarlyGate100-YN and pEarlyGate100-YC $[38,107]$ using the Gateway system (Invitrogen). Four-week-old $N$. bentamiana leaves were infiltrated as described previously [108] with two constructs expressing GSL8-YC and the candidate interactors fused to YN. Three days post infiltration (dpi), the fluorescent cells' images were captured on a Leica TCS SP2 Laser Scanning confocal microscope (Leica) [109] using $514 \mathrm{~nm}$ excitation and 515 to $545 \mathrm{~nm}$ emission. Primers used in generation of BiFC constructs are listed in Additional file 1: Table S6.

\section{Förster resonance energy transfer}

To test the interaction of GSL8 with candidate partners, their full-length cDNA was amplified from Arabidopsis cDNA pool and cloned into pEarleyGate101 and
pEarleyGate102 [104] using the Gateway system (Invitrogen) to generate YFP- and CFP-fusion proteins, respectively (see Additional file 1: Table S6). The infiltration was performed as described in BiFC with two constructs expressing GSL8-YFP and the candidate interactor fused to CFP. The FRET between two proteins was quantified 3dpi using acceptor photobleaching method by imaging on a Leica TCS SP2 Laser Scanning confocal microscope (Leica) [109]. Images of the CFP fluorescence, for donor protein, and YFP fluorescence for acceptor proteins were captured using $458 \mathrm{~nm}$ excitation and 465 to $505 \mathrm{~nm}$ emissions, and $514 \mathrm{~nm}$ excitation and 525 to $600 \mathrm{~nm}$ emission, respectively. The fluorescence of the CFP and YFP channels were scanned before and after bleaching. Bleaching of the acceptor protein fluorescence was performed using 100\% excitation of $514 \mathrm{~nm}$ beam for 50 frames. The energy transfer efficiency between the two protein pairs was measured based on the fluorescence intensity change in the donor and acceptor, before and after photobleaching. Three independent experiments with at least three biological replicates for each pair were used to calculate FRET efficiency.

\section{Membrane yeast two-hybrid}

The MYTH system was used as described by Snider et al. [71]. Prey constructs were cloned in the pPR3-C and bait construct was cloned in the pAMBV vectors. The cDNA were cloned by 'gap-repair' homologous recombination in yeast [110]. After co-transformation of bait and prey vectors, presence of interaction was analysed by comparing colony growth on transformation selection media (TSM) (SD-Leu-Trp) and interaction selection media (ISM) (SD-Leu-Trp-Ade-His).

\section{Microscopy and image analysis}

Images were captured by a Nikon SMZ1500 (Nikon) dissecting or Zeiss Axioscope 2 (Zeiss) compound light microscopes which were integrated with a Nikon DS-Ri2 digital camera using the ACT-1 software (Nikon). Nikon dissecting scope optical ranges varied between 0.75 and $11.5 \mathrm{X}$, and the compound Zeiss microscope was used with 20 and 40X objectives. TIFF format at a resolution of $3840 \times 3072$ pixels was used for capturing all images. The ImageJ software [111] was used to quantify callose and measuring GFP intensity levels on unmodified root images. Callose quantification at the PD was carried out as previously described [112]. The endodermal-to-stele ratio of SHR-GFP was measured in the WT and gsl8 mutants as earlier described [59]. Briefly, the level of SHR-GFP fluorescence was measured in the endodermis and expressed as a ratio of stele fluorescence. To determine the level of fluorescence in each given region, e.g. endodermis or stele, the corrected total cell fluorescence 
(CTCF) was calculated using the following formula: CTCF = Integrated Density - (Area of selected cell X Mean fluorescence of background readings) [113-115]. The average for the WT control was set to 1 , and the intensity ratio in the mutants was calculated relative to the WT. Statistics were done using Excel (Microsoft Office). A minimum of 10 and maximum of 20 roots were used for both callose intensity and SHR-GFP quantification analysis.

\section{Accession numbers}

Sequence data used in this article can be found on the Arabidopsis Information Resource (TAIR) database under the following accession numbers: GSL1 (AT4G049 70), GSL2 (AT2G13680), GSL3 (AT2G31960), GSL4 (AT 3G14570), GSL5 (AT4G03550), GSL6 (AT1G05570), GS L7 (AT1G06490), GSL8 (AT2G36850), GSL9 (AT5G368 70), GSL10 (AT3G07160), GSL11 (AT3G59100), GSL12 (AT5G13000), HINKEL (AT1G18370), KNOLLE (At1G0 8560), KEULE (AT1G12360), KORRIGAN (AT5G49720), SCD1 (AT1G49040), SHR (AT4G37650), SCR (AT3G5 4220), UDPG (AT1G16570), SUS1 (AT5G20830), AtBG_ PPAP (At5G42100), PDLP5 (AT1G70690).

\section{Additional files}

Additional file 1 Figure S1. Mapping of the essp8 mutation. Figure S2. ESSP8 is an allele of GSL8. Figure S3. Morphological phenotype of $g s / 8$ mutants' primary root showing severe defects in root tissue patterning. Figure S4. Genetic complementation of essp8 seedlings. Figure S5. Morphological phenotype of cytokinesis-defective mutants. Figure $\mathbf{S 6 .}$ Movement of fluorescent probes in essp8 hypocotyls. Figure S7. SCR relative expression in essp8 primary root compared to WT. Figure $\mathbf{S 8}$. Phylogenetic tree of Arabidopsis GSLs. Figure S9. Subcellular localization of the putative callose synthase complex components using their YFP fusions in transiently transformed N. bentamiana epithelial cell. Figure S10. FRET assay: Images of CFP and YFP fluorescent before and after bleaching. Figure S11. Morphological phenotype of the XVE:aMIRGSL8/GSL10 seedlings. (PDF $10100 \mathrm{~kb}$ )

Additional file $\mathbf{2}$ Table S1. Segregation of homozygous essp8 seedlings in the progeny of selfed ESSP8/essp8 heterozygous plants. Table S2. The percentage of defective seeds in one silique from selfed ESSP8/essp8 heterozygous plants. Table S3. Segregation of homozygous gs/8 T-DNA insertion seedlings in the progeny of selfed heterozygous plants. Table S4. List of mutant lines and primers used for genotyping. Table S5. List of primers used for essp8 rough-mapping. Table $\mathbf{S 6}$. List of primers used for cloning and qPCR. (PDF $210 \mathrm{~kb}$ )

\section{Abbreviations}

Cals: Callose synthase; dpi: Days post-infiltration; GFP: Green fluorescent protein; GSL: Glucan synthase; PD: Plasmodesmata; SEL: Size exclusion limit

\section{Acknowledgments}

We thank the Arabidopsis Biological Resource Center (ABRC) for seeds of TDNA insertion lines and A. Molnar for help with the preparation of figures. We also thank Dr. S. Dhaubhadel (Agriculture and Agri-Food Canada, London, Ontario, Canada) for donating the GmIFS2-YN construct.

\section{Funding}

This work was supported by funding from the Agriculture and Agri-Food Canada A-Base and the National Science and Engineering Research Council of Canada (R4019A01). The funder did not play any roles in the design of the study, collection, analysis and interpretation of the relevant data, and writing the manuscript. C. Chen was supported by a graduate scholarship from the China Scholarship Council.

\section{Availability of data and materials}

The datasets used and/or analyzed during the current study are available from the corresponding author on reasonable request.

\section{Authors' contributions}

BS and YC developed the project and designed the experiments. BS, RSA, GT and CC conducted next-generation mapping, acquisition of NGM data and the analysis. BS, GT and CC interpreted NGM data. DG provided the construct and experimental methods on centromere labeling and revised the manuscript critically. VN carried out all the Sanger DNA sequencing, data acquisition and analysis. BS performed all the rest of the experiments, data collection and analysis, and interpretation. BS, and YC wrote the paper. SEK critically revised the manuscript. All authors reviewed and gave final approval of the version to be published.

Ethics approval and consent to participate

Not applicable.

\section{Consent for publication}

Not applicable.

\section{Competing interests}

The authors declare that they have no competing interests.

\section{Publisher's Note}

Springer Nature remains neutral with regard to jurisdictional claims in published maps and institutional affiliations.

\section{Author details \\ ${ }^{1}$ Agriculture and Agri-Food Canada, London Research and Development Centre, London, ON, Canada. ${ }^{2}$ Department of Biology, Western University, 1391 Sandford St, London, ON N5V 4T3, Canada. ${ }^{3}$ In Vitro Biology and Horticulture, Department of Plant Production, University of Ghent, 9000 Ghent, Belgium.}

Received: 16 October 2017 Accepted: 31 October 2018 Published online: 22 November 2018

\section{References}

1. Lerouxel O, Cavalier DM, Liepman AH, Keegstra K. Biosynthesis of plant cell wall polysaccharides - a complex process. Curr Opin Plant Biol. 2006;9(6):621-30.

2. Chen X-Y, Kim J-Y. Callose synthesis in higher plants. Plant Signal Behav. 2009;4(6):489-92.

3. Levy A, Guenoune-Gelbart D, Epel BL. Plasmodesmal gate keepers for intercellular communication. Plant J. 2006;49:669-82.

4. Lucas WJ, Ham B-K, Kim J-Y. Plasmodesmata-bridging the gap between neighboring plant cells. Trends Cell Biol. 2009;19(10):495-503.

5. Maule AJ, Benitez-Alfonso Y, Faulkner C. Plasmodesmata-membrane tunnels with attitude. Curr Opin Plant Biol. 2011;14(6):683-90.

6. Zavaliev R, Ueki S, Epel BL, Citovsky V. Biology of callose ( $\beta$-1, 3-glucan) turnover at plasmodesmata. Protoplasma. 2011;248(1):117-30.

7. Xie B, Deng Y, Kanaoka MM, Okada K, Hong Z. Expression of Arabidopsis callose synthase 5 results in callose accumulation and cell wall permeability alteration. Plant Sci. 2012:183:1-8.

8. Piršelová B, Matušíková I. Callose: the plant cell wall polysaccharide with multiple biological functions. Acta Physiol Plant. 2013;35(3):635-44.

9. Assaad FF. Plant cytokinesis. Exploring the links. Plant Physiol. 2001;126(2): 509-16.

10. Söllner R, Glässer $G$, Wanner $G$, Somerville $C R$, Jürgens $G$, Assaad FF. Cytokinesis-defective mutants of Arabidopsis. Plant Physiol. 2002;129(2):678-90

11. Samuels AL, Giddings TH, Staehelin LA. Cytokinesis in tobacco BY-2 and root tip cells: a new model of cell plate formation in higher plants. J Cell Biol. 1995;130(6):1345-57.

12. Hatzfeld J, Buttin G. Temperature-sensitive cell cycle mutants: a Chinese hamster cell line with a reversible block in cytokinesis. Cell. 1975;5(2):123-9. 
13. Karess RE, X-j C, Edwards KA, Kulkarni S, Aguilera I, Kiehart DP. The regulatory light chain of nonmuscle myosin is encoded by spaghetti-squash, a gene required for cytokinesis in Drosophila. Cell. 1991;65(7):1177-89.

14. Liu Z, Running MP, Meyerowitz EM. TSO1 functions in cell division during Arabidopsis flower development. Development. 1997;124(3):665-72.

15. Lordier L, Jalil A, Aurade F, Larbret F, Larghero J, Debili N, Vainchenker W, Chang Y. Megakaryocyte endomitosis is a failure of late cytokinesis related to defects in the contractile ring and rho/rock signaling. Blood. 2008;112(8):3164-74.

16. Pampalona J, Frías C, Genescà A, Tusell L. Progressive telomere dysfunction causes cytokinesis failure and leads to the accumulation of polyploid cells. PLoS Genet. 2012;8(4):e1002679.

17. Stahl Y, Simon R. Gated communities: apoplastic and symplastic signals converge at plasmodesmata to control cell fates. J Exp Bot. 2013;64(17):5237-41.

18. Kitagawa M, Paultre D, Rademaker H. Intercellular communication via plasmodesmata. New Phytol. 2015;205(3):970-2.

19. Yadav SR, Yan D, Sevilem I, Helariutta Y. Plasmodesmata-mediated intercellular signaling during plant growth and development. Front Plant Sci. 2014;5(44):1-7.

20. De Storme N, Geelen D. Callose homeostasis at plasmodesmata: molecular regulators and developmental relevance. Front Plant Sci. 2014;5(138):1-23.

21. Richmond TA, Somerville CR. Integrative approaches to determining CsI function. In: Plant cell walls. Netherlands: Springer; 2001. p. 131-43.

22. Verma DPS, Hong Z. Plant callose synthase complexes. Plant Mol Biol. 2001; 47(6):693-701.

23. Hayashi T, Read S, Bussell J, Thelen M, Lin F-C, Brown R, Delmer D. UDPglucose: $(1 \rightarrow 3)-\beta$-glucan synthases from mung bean and cotton: differential effects of $\mathrm{Ca}^{2+}$ and $\mathrm{Mg}^{2+}$ on enzyme properties and on macromolecular structure of the glucan product. Plant Physiol. 1987;83(4):1054-62.

24. Andrawis A, Solomon M, Delmer DP. Cotton fiber annexins: a potential role in the regulation of callose synthase. Plant J. 1993;3(6):763-72.

25. Li H, Bacic A, Read SM. Activation of pollen tube callose synthase by detergents (evidence for different mechanisms of action). Plant Physiol. 1997:114(4):1255-65.

26. Li H, Bacic A, Read SM. Role of a callose synthase zymogen in regulating wall deposition in pollen tubes of Nicotiana alata. Planta. 1999;208(4):528-38.

27. Cui $X$, Shin $H$, Song C, Laosinchai W, Amano Y, Brown MR. A putative plant homolog of the yeast $\beta$-1,3-glucan synthase subunit FKS1 from cotton (Gossypium hirsutum L.) fibers. Planta. 2001;213(2):223-30.

28. Cui W, Lee J-Y. Arabidopsis callose synthases CalS1/8 regulate plasmodesmal permeability during stress. Nature Plants. 2016;2:16034

29. Vatén A, Dettmer J, Wu S, Stierhof Y-D, Miyashima S, Yadav SR, Roberts CJ, Campilho A, Bulone V, Lichtenberger R. Callose biosynthesis regulates symplastic trafficking during root development. Dev Cell. 2011;21(6):1144-55.

30. Guseman JM, Lee JS, Bogenschutz NL, Peterson KM, Virata RE, Xie B, Kanaoka MM, Hong Z, Torii KU. Dysregulation of cell-to-cell connectivity and stomatal patterning by loss-of-function mutation in Arabidopsis CHORUS (GLUCAN SYNTHASE-LIKE 8). Development. 2010;137(10):1731-41.

31. Xie B, Wang $X$, Zhu M, Zhang Z, Hong Z. CalS7 encodes a callose synthase responsible for callose deposition in the phloem. Plant J. 2011;65(1):1-14.

32. Schmid M, Davison TS, Henz SR, Pape UJ, Demar M, Vingron M, Schölkopf B, Weigel D, Lohmann JU. A gene expression map of Arabidopsis thaliana development. Nat Genet. 2005;37(5):501-6.

33. Chen X-Y, Liu L, Lee E, Han X, Rim Y, Chu H, Kim S-W, Sack F, Kim J-Y. The Arabidopsis callose synthase gene GSL8 is required for cytokinesis and cell patterning. Plant Physiol. 2009;150(1):105-13.

34. Töller A, Brownfield L, Neu C, Twell D, Schulze-Lefert P. Dual function of Arabidopsis glucan synthase-like genes GSL8 and GSL10 in male gametophyte development and plant growth. Plant J. 2008;54(5):911-23.

35. De Storme N, De Schrijver J, Van Criekinge W, Wewer V, Dörmann P, Geelen D. GLUCAN SYNTHASE-LIKE8 and STEROL METHYLTRANSFERASE2 are required for ploidy consistency of the sexual reproduction system in Arabidopsis. Plant Cell. 2013;25(2):387-403.

36. Thiele K, Wanner G, Kindzierski V, Jürgens G, Mayer U, Pachl F, Assaad FF. The timely deposition of callose is essential for cytokinesis in Arabidopsis. Plant J. 2009;58(1):13-26

37. Tang X, Hou A, Babu M, Nguyen V, Hurtado L, Lu Q, Reyes JC, Wang A, Keller WA, Harada JJ. The Arabidopsis BRAHMA chromatin-remodeling ATPase is involved in repression of seed maturation genes in leaves. Plant Physiol. 2008;147(3):1143-57.
38. Lu Q, Tang XR, Tian G, Wang F, Liu KD, Nguyen V, Kohalmi SE, Keller WA, Tsang EWT, Harada JJ, et al. Arabidopsis homolog of the yeast TREX-2 mRNA export complex: components and anchoring nucleoporin. Plant J. 2010:61(2):259-70.

39. Tang X, Bian S, Tang M, Lu Q, Li S, Liu X, Tian G, Nguyen V, Tsang EW, Wang A. MicroRNA-mediated repression of the seed maturation program during vegetative development in Arabidopsis. PLoS Genet. 2012;8(11):e1003091.

40. Li C, Chen C, Gao L, Yang S, Nguyen V, Shi X, Siminovitch K, Kohalmi SE, Huang S, Wu K. The Arabidopsis SWI2/SNF2 chromatin remodeler BRAHMA regulates polycomb function during vegetative development and directly activates the flowering repressor gene SVP. PLoS Genet. 2015;11(1):e1004944.

41. Tang $X$, Lim M-H, Pelletier J, Tang M, Nguyen V, Keller WA, Tsang EWT, Wang A, Rothstein SJ, Harada JJ, et al. Synergistic repression of the embryonic programme by SET DOMAIN GROUP 8 and EMBRYONIC FLOWER 2 in Arabidopsis seedlings. J Exp Bot. 2012;63(3):1391-404.

42. Chen C, Li C, Wang Y, Renaud J, Tian G, Kambhampati S, Saatian B, Nguyen V, Hannoufa A, Marsolais F. Cytosolic acetyl-CoA promotes histone acetylation predominantly at H3K27 in Arabidopsis. Nature Plants. 2017;3:814-24.

43. Tsirigos KD, Peters C, Shu N, Käll L, Elofsson A. The TOPCONS web server for consensus prediction of membrane protein topology and signal peptides. Nucleic Acids Res. 2015;43:W401-7.

44. Simpson C, Thomas C, Findlay K, Bayer E, Maule AJ. An Arabidopsis GPIanchor plasmodesmal neck protein with callose binding activity and potential to regulate cell-to-cell trafficking. Plant Cell. 2009;21(2):581-94.

45. Joubès J, Chevalier C. Endoreduplication in higher plants. In: The plant cell cycle. Netherlands: Springer; 2000. p. 191-201.

46. Strompen G, El Kasmi F, Richter S, Lukowitz W, Assaad FF, Jürgens G, Mayer $U$. The Arabidopsis HINKEL gene encodes a kinesin-related protein involved in cytokinesis and is expressed in a cell cycle-dependent manner. Curr Biol. 2002:12(2):153-8.

47. Touihri S, Knöll C, Stierhof YD, Müller I, Mayer U, Jürgens G. Functional anatomy of the Arabidopsis cytokinesis-specific syntaxin KNOLLE. Plant J. 2011;68(5):755-64

48. Waizenegger I, Lukowitz W, Assaad F, Schwarz H, Jürgens G, Mayer U. The Arabidopsis KNOLLE and KEULE genes interact to promote vesicle fusion during cytokinesis. Curr Biol. 2000;10(21):1371-4.

49. Sato S, Kato T, Kakegawa K, Ishii T, Liu Y-G, Awano T, Takabe K, Nishiyama Y, Kuga S, Sato S. Role of the putative membrane-bound endo-1,4- $\beta$-glucanase KORRIGAN in cell elongation and cellulose synthesis in Arabidopsis thaliana. Plant Cell Physiol. 2001;42(3):251-63.

50. Falbel TG, Koch LM, Nadeau JA, Segui-Simarro JM, Sack FD, Bednarek SY. SCD1 is required for cell cytokinesis and polarized cell expansion in Arabidopsis thaliana. Development. 2003;130(17):4011-24.

51. De Storme N, Keçeli BN, Zamariola L, Angenon G, Geelen D. CENH3-GFP: a visual marker for gametophytic and somatic ploidy determination in Arabidopsis thaliana. BMC Plant Biol. 2016;16(1):1.

52. Han X, Hyun TK, Zhang M, Kumar R, E-j K, Kang B-H, Lucas WJ, Kim J-Y. Auxin-callose-mediated plasmodesmal gating is essential for tropic auxin gradient formation and signaling. Dev Cell. 2014;28(2):132-46.

53. Helariutta Y, Fukaki H, Wysocka-Diller J, Nakajima K, Jung J, Sena G, Hause M-T, Benfey PN. The SHORT-ROOT gene controls radial patterning of the Arabidopsis root through radial signaling. Cell. 2000;101(5):555-67.

54. Di Laurenzio L, Wysocka-Diller J, Malamy JE, Pysh L, Helariutta Y, Freshour G, Hahn MG, Feldmann KA, Benfey PN. The SCARECROW gene regulates an asymmetric cell division that is essential for generating the radial organization of the Arabidopsis root. Cell. 1996;86(3):423-33.

55. Wysocka-Diller JW, Helariutta Y, Fukaki H, Malamy JE, Benfey PN. Molecular analysis of SCARECROW function reveals a radial patterning mechanism common to root and shoot. Development. 2000;127(3):595-603.

56. Nakajima K, Sena G, Nawy T, Benfey PN. Intercellular movement of the putative transcription factor SHR in root patterning. Nature. 2001; 413(6853):307-11.

57. Wu S, Gallagher KL. The movement of the non-cell-autonomous transcription factor, SHORT-ROOT relies on the endomembrane system. Plant J. 2014;80(3):396-409.

58. Gallagher KL, Benfey PN. Both the conserved GRAS domain and nuclear localization are required for SHORT-ROOT movement. Plant J. 2009;57(5):785-97.

59. Koizumi K, Hayashi T, Wu S, Gallagher KL. The SHORT-ROOT protein acts as a mobile, dose-dependent signal in patterning the ground tissue. P Natl Acad Sci USA. 2012;109(32):13010-5. 
60. Benfey PN, Scheres B. Root development. Curr Biol. 2000;10(22):R813-5.

61. Carlsbecker A, Lee J-Y, Roberts CJ, Dettmer J, Lehesranta S, Zhou J, Lindgren O, Moreno-Risueno MA, Vatén A, Thitamadee S. Cell signalling by microRNA165/6 directs gene dose-dependent root cell fate. Nature. 2010; 465(7296):316-21.

62. Miyashima S, Koi S, Hashimoto T, Nakajima K. Non-cell-autonomous microRNA165 acts in a dose-dependent manner to regulate multiple differentiation status in the Arabidopsis root. Development. 2011;138(11):2303-13.

63. Parizotto EA, Dunoyer P, Rahm N, Himber C, Voinnet O. In vivo investigation of the transcription, processing, endonucleolytic activity, and functional relevance of the spatial distribution of a plant miRNA. Genes Dev. 2004; 18(18):2237-42.

64. Lee JY, Wang X, Cui W, Sager R, Modla S, Czymmek K, Zybaliov B, van Wijk K, Zhang $\mathrm{C}$, Lu H, et al. A plasmodesmata-localized protein mediates crosstalk between cell-to-cell communication and innate immunity in Arabidopsis. Plant Cell. 2011;23(9):3353-73.

65. Thomas CL, Bayer EM, Ritzenthaler C, Fernandez-Calvino L, Maule A. Specific targeting of a plasmodesmal protein affecting cell-to-cell communication. PLoS Biol. 2008;6(1):e7.

66. Shin H, Brown RM. GTPase activity and biochemical characterization of a recombinant cotton fiber annexin. Plant Physiol. 1999;1 19(3):925-34.

67. Hong Z, Delauney AJ, Verma DPS. A cell plate-specific callose synthase and its interaction with phragmoplastin. Plant Cell. 2001;13(4):755-68.

68. Hong Z, Zhang Z, Olson JM, Verma DPS. A novel UDP-glucose transferase is part of the callose synthase complex and interacts with phragmoplastin at the forming cell plate. Plant Cell. 2001;13(4):769-79.

69. McMichael CM, Reynolds GD, Koch LM, Wang C, Jiang N, Nadeau J, Sack FD, Gelderman MB, Pan J, Bednarek SY. Mediation of clathrin-dependent trafficking during cytokinesis and cell expansion by Arabidopsis STOMATAL CYTOKINESIS DEFECIVE proteins. Plant Cell. 2013;25(10):3910-25.

70. Dastmalchi M, Bernards MA, Dhaubhadel S. Twin anchors of the soybean isoflavonoid metabolon: evidence for tethering of the complex to the endoplasmic reticulum by IFS and C4H. Plant J. 2016;85(6):689-706.

71. Snider J, Kittanakom S, Damjanovic D, Curak J, Wong V, Stagljar I. Detecting interactions with membrane proteins using a membrane two-hybrid assay in yeast. Nat Protoc. 2010;5(7):1281-93.

72. Curtis MD, Grossniklaus U. A gateway cloning vector set for highthroughput functional analysis of genes in planta. Plant Physiol. 2003;133(2):462-9.

73. Verma DPS. Cytokinesis and building of the cell plate in plants. Annu Rev Plant Biol. 2001;52(1):751-84.

74. Sugimoto-Shirasu K, Roberts K. "Big it up": endoreduplication and cell-size control in plants. Curr Opin Plant Biol. 2003;6(6):544-53.

75. Castedo M, Perfettini J-L, Roumier T, Andreau K, Medema R, Kroemer G. Cell death by mitotic catastrophe: a molecular definition. Oncogene. 2004; 23(16):2825-37.

76. Vakifahmetoglu H, Olsson M, Zhivotovsky B. Death through a tragedy: mitotic catastrophe. Cell Death \& Differ. 2008;15(7):1153-62

77. McCall K. Eggs over easy: cell death in the Drosophila ovary. Dev Biol. 2004;274(1):3-14.

78. Pritchett T, Tanner E, McCall K. Cracking open cell death in the Drosophila ovary. Apoptosis. 2009;14(8):969-79.

79. Doelling JH, Yan N, Kurepa J, Walker J, Vierstra RD. The ubiquitin-specific protease UBP14 is essential for early embryo development in Arabidopsis thaliana. Plant J. 2001;27(5):393-405.

80. Tzafrir I, McElver JA, Liu C-m, Yang LJ, Wu JQ, Martinez A, Patton DA, Meinke DW. Diversity of TITAN functions in Arabidopsis seed development. Plant Physiol. 2002;128(1):38-51.

81. Levy A, Erlanger M, Rosenthal M, Epel BL. A plasmodesmata-associated

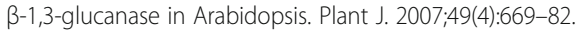

82. Benfey PN, Linstead PJ, Roberts K, Schiefelbein JW, Hauser M-T, Aeschbacher RA. Root development in Arabidopsis: four mutants with dramatically altered root morphogenesis. Development. 1993;119(1):57-70.

83. Cui H, Levesque MP, Vernoux T, Jung JW, Paquette AJ, Gallagher KL, Wang JY, Blilou I, Scheres B, Benfey PN. An evolutionarily conserved mechanism delimiting SHR movement defines a single layer of endodermis in plants. Science. 2007;316(5823):421-5.

84. Welch D, Hassan H, Blilou I, Immink R, Heidstra R, Scheres B. Arabidopsis JACKDAW and MAGPIE zinc finger proteins delimit asymmetric cell division and stabilize tissue boundaries by restricting SHORT-ROOT action. Genes Dev. 2007;21(17):2196-204.
85. Miyashima S, Nakajima K. The root endodermis: a hub of developmental signals and nutrient flow. Plant Signal Behav. 2011;6(12):1954-8.

86. Koizumi K, Hayashi T, Wu S, Gallagher KL. The SHORT-ROOT protein acts as a mobile, dose-dependent signal in patterning the ground tissue. Proc Nat Acad Sci. 2012;109(32):13010-5.

87. Prigge MJ, Otsuga D, Alonso JM, Ecker JR, Drews GN, Clark SE. Class III homeodomain-leucine zipper gene family members have overlapping, antagonistic, and distinct roles in Arabidopsis development. Plant Cell. 2005;17(1):61-76.

88. Hirakawa $Y$, Kondo $Y$, Fukuda $\mathrm{H}$. Establishment and maintenance of vascular cell communities through local signaling. Curr Opin Plant Biol. 2011;14(1):17-23.

89. Xie B, Wang X, Zhu M, Zhang Z, Hong Z. CALS7 encodes a callose synthase responsible for callose deposition in the phloem. Plant J. 2011;65(1):1-14.

90. Barratt DP, Kölling K, Graf A, Pike M, Calder G, Findlay K, Zeeman SC, Smith AM. Callose synthase GSL7 is necessary for normal phloem transport and inflorescence growth in Arabidopsis. Plant Physiol. 2011:155(1):328-41.

91. Barratt DH, Kolling K, Graf A, Pike M, Calder G, Findlay K, Zeeman SC, Smith AM. Callose synthase GSL7 is necessary for normal phloem transport and inflorescence growth in Arabidopsis. Plant Physiol. 2011;155(1):328-41.

92. Coleman HD, Yan J, Mansfield SD. Sucrose synthase affects carbon partitioning to increase cellulose production and altered cell wall ultrastructure. Proc Natl Acad Sci. 2009;106(31):13118-23.

93. Salnikov W, Grimson MJ, Delmer DP, Haigler CH. Sucrose synthase localizes to cellulose synthesis sites in tracheary elements. Phytochemistry. 2001; 57(6):823-33.

94. Brunkard JO, Runkel AM, Zambryski PC. Plasmodesmata dynamics are coordinated by intracellular signaling pathways. Curr Opin Plant Biol. 2013; 16(5):614-20.

95. Gardiner JC, Taylor NG, Turner SR. Control of cellulose synthase complex localization in developing xylem. Plant Cell. 2003;15(8):1740-8.

96. Atanassov II, Pittman JK, Turner SR. Elucidating the mechanisms of assembly and subunit interaction of the cellulose synthase complex of Arabidopsis secondary cell walls. J Biol Chem. 2009;284(6):3833-41.

97. Lukowitz W, Gillmor CS, Scheible W-R. Positional cloning in Arabidopsis. Why it feels good to have a genome initiative working for you. Plant Physiol. 2000;123(3):795-806.

98. Austin RS, Vidaurre D, Stamatiou G, Breit R, Provart NJ, Bonetta D, Zhang J, Fung P, Gong Y, Wang PW. Next-generation mapping of Arabidopsis genes. Plant J. 2011:67(4):715-25.

99. Suzuki T, Fujikura K, Higashiyama T, Takata K. DNA staining for fluorescence and laser confocal microscopy. J Histochem Cytochem. 1997:45(1):49-53.

100. Hartley JL, Temple GF, Brasch MA. DNA cloning using in vitro site-specific recombination. Genome Res. 2000;10(11):1788-95.

101. Zhang X, Henriques R, Lin S-S, Niu Q-W, Chua N-H. Agrobacterium-mediated transformation of Arabidopsis thaliana using the floral dip method. Nat Protoc. 2006; 1(2):641-6.

102. Kouprina $\mathrm{N}$, Larionov V. Selective isolation of genomic loci from complex genomes by transformation-associated recombination cloning in the yeast Saccharomyces cerevisiae. Nat Protoc. 2008;3(3):371-7.

103. Karas BJ, Jablanovic J, Irvine E, Sun L, Ma L, Weyman PD, Gibson DG, Glass JI, Venter JC, Hutchison CA III. Transferring whole genomes from bacteria to yeast spheroplasts using entire bacterial cells to reduce DNA shearing. Nat Protoc. 2014:9(4):743-50.

104. Earley KW, Haag JR, Pontes O, Opper K, Juehne T, Song KM, Pikaard CS. Gateway-compatible vectors for plant functional genomics and proteomics. Plant J. 2006;45(4):616-29.

105. Schwab R, Ossowski S, Riester M, Warthmann N, Weigel D. Highly specific gene silencing by artificial microRNAs in Arabidopsis. Plant Cell. 2006; 18(5):1121-33.

106. Czechowski T, Stitt M, Altmann T, Udvardi MK, Scheible W-R. Genome-wide identification and testing of superior reference genes for transcript normalization in Arabidopsis. Plant Physiol. 2005;139(1):5-17.

107. Tian G, Lu Q, Zhang L, Kohalmi SE, Cui Y. Detection of protein interactions in plant using a gateway compatible bimolecular fluorescence complementation (BiFC) system. JoVE J Vis Exp. 2011;(55):-e3473. https://doi.org/10.3791/3473.

108. Sparkes IA, Runions J, Kearns A, Hawes C. Rapid, transient expression of fluorescent fusion proteins in tobacco plants and generation of stably transformed plants. Nat Protoc. 2006; 1(4):2019-25. 
109. Karpova T, McNally JG. Detecting protein-protein interactions with CFPYFP FRET by acceptor photobleaching. Curr Protoc Cytom. 2006;12.17:11-12.17 11 .

110. Vo KT, Michaelis S, Paddon C. Recombination-mediated PCR-directed plasmid construction in vivo in yeast. Nucleic Acids Res. 1997;25(2):451-2.

111. Schneider CA, Rasband WS, Eliceiri KW. NIH image to ImageJ: 25 years of image analysis. Nat Methods. 2012;9(7):671-5.

112. Zavaliev R, Epel BL. Imaging Callose at Plasmodesmata Using Aniline Blue: Quantitative Confocal Microscopy. Plasmodesmata Methods Protoc. 2015; 1217:105-19.

113. McCloy RA, Rogers S, Caldon CE, Lorca T, Castro A, Burgess A. Partial inhibition of Cdk1 in G2 phase overrides the SAC and decouples mitotic events. Cell Cycle. 2014;13(9):1400-12.

114. Burgess A, Vigneron S, Brioudes E, Labbé J-C, Lorca T, Castro A. Loss of human Greatwall results in $\mathrm{G} 2$ arrest and multiple mitotic defects due to deregulation of the cyclin B-Cdc2/PP2A balance. Proc Natl Acad Sci. 2010; 107(28):12564-9

115. Gavet O, Pines J. Progressive activation of CyclinB1-Cdk1 coordinates entry to mitosis. Dev Cell. 2010;18(4):533-43.

Ready to submit your research? Choose BMC and benefit from:

- fast, convenient online submission

- thorough peer review by experienced researchers in your field

- rapid publication on acceptance

- support for research data, including large and complex data types

- gold Open Access which fosters wider collaboration and increased citations

- maximum visibility for your research: over $100 \mathrm{M}$ website views per year

At $\mathrm{BMC}$, research is always in progress.

Learn more biomedcentral.com/submissions 